\title{
Axon-bearing and axon-less horizontal cell subtypes are generated consecutively during chick retinal development from progenitors that are sensitive to follistatin
}

\author{
Per-Henrik D Edqvist, Madelen Lek, Henrik Boije, Sarah M Lindbäck and \\ Finn Hallböök*
}

Address: Department of Neuroscience, Unit of Developmental Neuroscience, Biomedical Centre, Uppsala University, S-751 23, Uppsala, Sweden Email: Per-Henrik D Edqvist - per-henrik.edqvist@neuro.uu.se; Madelen Lek - madelen.lek@neuro.uu.se; Henrik Boije - henrik.boije@neuro.uu.se; Sarah M Lindbäck - sarah.lindback@gmail.com; Finn Hallböök* - finn.hallbook@neuro.uu.se * Corresponding author

Published: 25 April 2008

BMC Developmental Biology 2008, 8:46 doi:10.1/86/147|-2/3X-8-46

This article is available from: http://www.biomedcentral.com/l47I-2/3X/8/46

(C) 2008 Edqvist et al; licensee BioMed Central Ltd.

This is an Open Access article distributed under the terms of the Creative Commons Attribution License (http://creativecommons.org/licenses/by/2.0), which permits unrestricted use, distribution, and reproduction in any medium, provided the original work is properly cited.
Received: 22 October 2007

Accepted: 25 April 2008

\begin{abstract}
Background: Horizontal cells are retinal interneurons that modulate the output from photoreceptors. A rich literature on the morphological classification and functional properties of $\mathrm{HCs}$ in different animals exists, however, the understanding of the events underlying their development is still limited. In most vertebrates including chicken, two main horizontal cell (HC) subtypes are identified based on the presence or absence of an axon.

Results: In this work we have molecularly characterized three $\mathrm{HC}$ subtypes based on Lim I, IsI I, GABA and TrkA, a classification that is consistent with three chick $\mathrm{HC}$ subtypes previously defined by morphology. The axon-bearing and axon-less $\mathrm{HC}$ subpopulations molecularly defined by Lim I and $|s| I$, are born consecutively on embryonic day (E) 3-4 and E4-5, respectively, and exhibit temporally distinguishable periods of migration. Their relative numbers are not adjusted by apoptosis. A sharp decrease of high endogenous levels of the activin-inhibitor follistatin at E3 coincides with the appearance of the Lim I positive cells. Extending the follistatin exposure of the $\mathrm{HC}$ retinal progenitor cells by injection of follistatin at E3 increased the number of both Lim I- and Isll positive $\mathrm{HCs}$ when analysed at $\mathrm{E}$.

Conclusion: The results imply that the axon-bearing and axon-less HC subgroups are defined early and are generated consecutively from a retinal progenitor cell population that is sensitive to the inhibitory action of follistatin. The results are consistent with a model wherein added follistatin causes $\mathrm{HC}$-generating progenitors to proliferate beyond the normal period of $\mathrm{HC}$ generation, thus producing extra $\mathrm{HCs}$ of both types that migrate to the $\mathrm{HC}$ layer.
\end{abstract}

\section{Background}

During the development of the vertebrate retina, five types of neurons are born in a preserved sequential but overlapping order [1-3]. These are retinal ganglion cells, horizontal cells (HCs), amacrine cells, bipolar cells and photoreceptors. In the mature retina, these cell types are positioned within distinct laminas and can be further divided into subtypes based on morphology, neurochemical properties or function. At the end of the $19^{\text {th }}$ century, Ramón y Cajal recognized this complex lamination and 
morphological richness of the retina as well as identified retinal subtypes based on morphology. Today, neuronal subtypes are defined and distinguished by molecular and functional criteria rather than by morphology. Approximately 50-70 neuronal subtypes can be identified in the mature retina depending on the species $[4,5]$.

Horizontal cells, which are the focus of this study, have been found in all vertebrate retinas from fish to man $[6,7]$. They are interneurons situated between photoreceptors and bipolar cells and form synapses with both cell types. In the chick retina, HCs form a distinct layer of cells that we will refer to as the horizontal cell layer (HCL), in the outermost part of the inner nuclear layer (INL). Two kinds of HCs are found in vertebrate retinas; axon-bearing and axon-less HCs [6,7]. An exception are retinas from several rodents, including mice, where only one HC type is identified [8]. In several species of fish, turtles, birds and mammals (including primates) a third HC subtype have been identified or suggested [4,6,9-12]. Regardless of the actual number of HC subtypes, the axon-bearing HC is present in all species and additional subtypes are axon-less [6]. The chick retina has three HC subtypes that have been identified based on their distinct morphological appearances $[13,14]$. One is the axon-bearing "brush-shaped" HC (also denoted H1 or Type I) and the two others are axon-less HCs, denoted "stellate" (or H2/Type II) and "candelabrum-shaped" (or H3/Type III) HCs. The brushshaped HC axon-terminus mainly connects to rod photoreceptors, whereas the dendritic trees of all three HCs mainly form connections with cone photoreceptors $[13,15,16]$. This functional organisation appears to be conserved within vertebrate retinas $[6,7]$.

A rich literature on the morphological and functional properties of HC subtypes exists but less is known about the developmental events underlying their generation. Recent studies have demonstrated that transcription factors such as Foxn4, Ptf1a and Prox1 are pivotal for the generation of the axon-bearing HCs in mice [17-21], and retinas deficient of the cell cycle inhibitors Ink4d and Kip1 overproduce those HCs [22]. In addition to intrinsic regulators like these, extrinsic factors are known to modulate different aspects of retinal development including proliferation, determination, differentiation and cell survival/death. Members of the transforming growth factor $\beta /$ bone morphogenetic protein (TGF $\beta / B M P$ ) family of growth factors are known to function as modulators during neuronal development [23] and an involvement of these molecules during the generation of retinal neurons have been suggested [24-30]. Follistatin which is an endogenous inhibitor of activin, TGF- $\beta$ 1, GDF-11, and several other TGF $\beta / B M P$ molecules $[27,31]$, is known to be expressed in the developing retina and pigment epithelium $[24,25]$. Interestingly, a recent study indicated that the generation of HCs may be affected by follistatin [28] since Prox $1+$ cells were found scattered at ectopic locations following virus mediated over-expression of follistatin in the developing retina.

The aim of this study was to gain further understanding of how and when HC subtypes are generated. We have molecularly characterized HC subtypes and found that the transcription factors Lim 1 and Isl1 are expressed in axon-bearing and axon-less HC subtypes, respectively. We demonstrate that the axon-bearing and axon-less HC subpopulations are molecularly defined early in development, have different but overlapping birth dates, migrate to the HCL at different times and that their relative numbers are not adjusted by apoptosis. Endogenous follistatin expression is high during the earliest phase of retinal development, with levels dropping sharply at the time of HC generation. Moreover, we show that follistatin overexposure at the time of HC-generation causes an increase in both the early-generated Lim1+ axon-bearing and late Isl1 + axon-less HCs when analyzed at embryonic day 9/ Hamburger \& Hamilton stage 35 (E9, st35, [32]). Combined, these results imply that the two HC subgroups are defined early and are generated consecutively from a progenitor cell population that is sensitive to follistatin inhibition.

\section{Results \\ Newly generated HCs express either Lim I or IsII and constitute equally large populations}

To identify immature HC subtypes several available antibodies against molecules known to be involved in neuronal determination were surveyed for reactivity to HCs. In addition to the transcription factors Prox 1 and Lim1 that are expressed by immature HCs, Isl1 was identified as a novel transcription factor expressed in immature HCs. The result of the antibody survey is reported elsewhere [33]. First we analysed whether all HCs expressed Prox1 and Pax6, two well established HC markers, using flatmounted retina sectioned through the HCL. The analysis showed that all cells located within the HCL expressed Prox1 and Pax6 (not shown). Stage 35 (E9) was selected for further analysis since the HCL is established within the INL at this age [34]. Retinas were analysed with respect to Prox1, Lim1 and Isl1 expression. The results showed that Lim1 and Isl1 immunoreactivities did not overlap, and that Lim1 and Isl1 immunoreactive HCs were mixed within the HCL (Fig. 1A). By counting double-labelled cells in the HCL of the central-most retina, the ratio of Lim $1+$ or Isl1+ HCs were determined to be 50/50 with respect to Prox1 (Fig. 1B). These results reveal that HCs are split into two equally large sub-groups based on the expression of Lim1 and Isl1. 

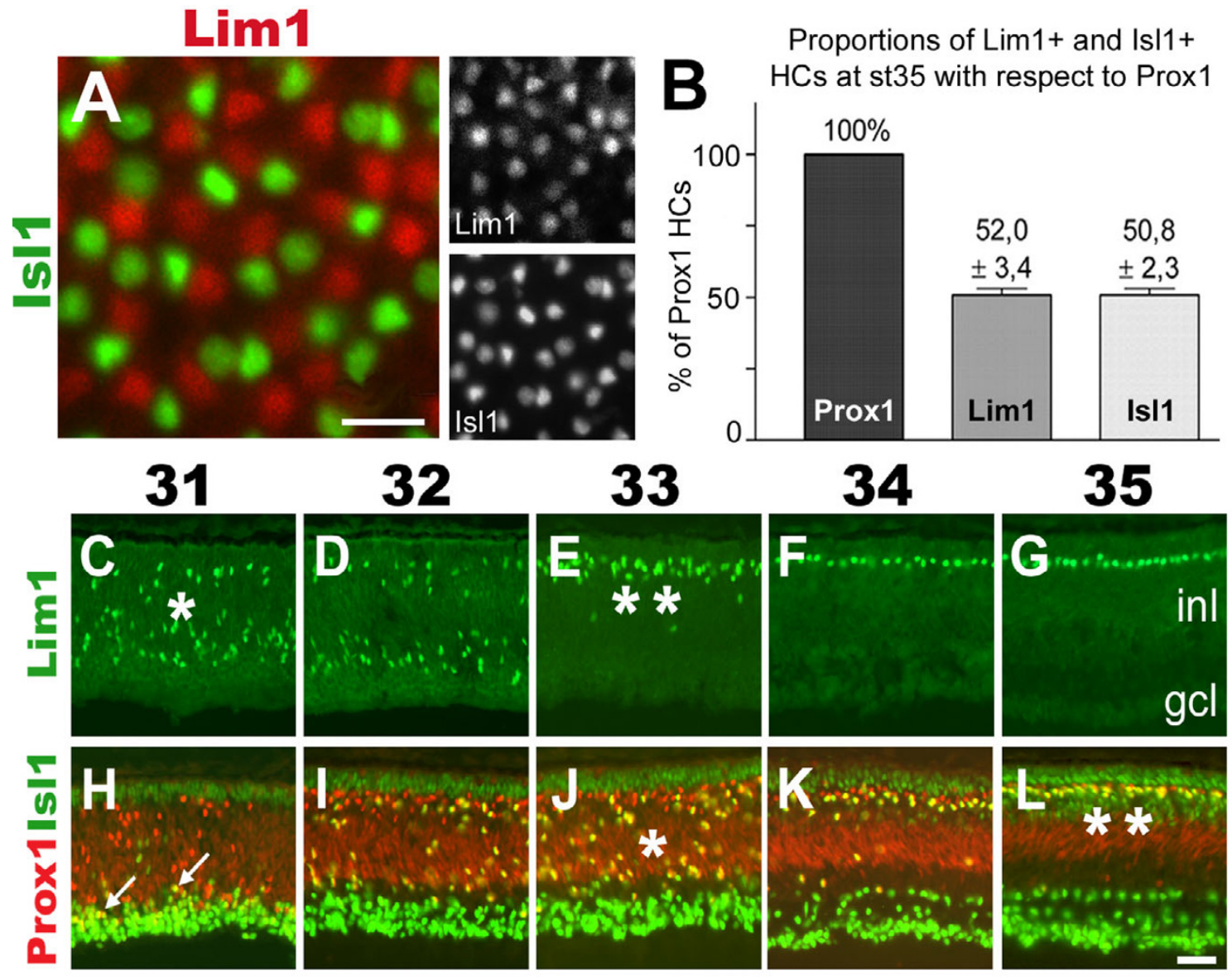

\section{Figure I}

Horizontal cells express either Lim I or IsII in equally large proportions. (A): The HCL of a flat-mounted normal retina section labelled for Lim I (red) and Isl I (green) reveals that the expression patterns do not overlap. (B): Quantification of HCs expressing Lim I or Isl I with respect to Proxl at st35 (expressed as \% \pm s.d., $n$ animals $=3$ ). (C-L): Comparison of the labelling patterns of Lim I (C-G, green) and Proxl combined with IsII (H-L, red/green) in st3 I-35 (E7-E9) retinas reveal that Lim I and IsII HCs migrate $\left(^{*}\right)$ and reach the $\mathrm{HCL}\left({ }^{* *}\right)$ at different time points. White arrows in $\mathrm{H}$ indicate double-labelled cells. Scale bars are $20 \mu \mathrm{m}(\mathrm{A})$ and $40 \mu \mathrm{m}$ (L, valid for C-L).

\section{Isl I HCs migrate one day after the LimI HCs}

We have previously shown that HCs expressing Lim 1 and Prox1 perform a bi-directional migration within the retina [34]. We investigated whether Isl 1 + HCs performed a similar bi-directional migration by comparing the patterns of Lim1 (Fig. 1C-G), Prox1 (Fig. 1H-L, red) and Isl1 (Fig. $1 \mathrm{H}-\mathrm{L}$, green). The spatio-temporal pattern of Prox1+, Isl1+ double-labelled cells was similar, but delayed to, the Prox1+, Lim1+ double-labelled cells that have been shown to migrate bi-directionally (compare Fig. 1C with $1 \mathrm{~J}$ and $1 \mathrm{E}$ with $1 \mathrm{~L}$, single and double asterisks). The first Prox1+, Isl1+ double-labelled cells were detected close to the prospective ganglion cell layer (GCL) at st31 (Fig. 1H, white arrows pointing at yellow cells). During subsequent stages numerous Prox1, Isl1 double-positive cells were seen scattered at various levels of the INL between st32 and st35 (Fig. 1H-L, yellow cells). Our analysis suggests that Prox1+, Isl1+ double-labelled cells initiate retrograde migration and reach the HCL one day after Lim1+ HCs.

\section{IsI I HCs are born one day after Lim I HCs}

To investigate if the segregated migration patterns reflected a temporal difference in birth-dates or just a delay in migration between the two subgroups, we birthdated the two HC populations using $\left[{ }^{3} \mathrm{H}\right]-\mathrm{dT}$. Stage 19-33 embryos received a single dose of $\left[{ }^{3} \mathrm{H}\right]$-dT after which retinas were collected at st35 (E9) and processed for Lim1 and Prox 1 immunocytochemistry and autoradiography. Stage 35 was analyzed since the mature 50/50 ratio of Lim 1+ and Isl1+ HCs is set at this stage (see below and Fig. 1B). The fractions of Lim1+ or Prox1+ HCs also positive for $\left[{ }^{3} \mathrm{H}\right]$-dT incorporation (silver grains) were determined 
for each injected stage (see Additional files 1 and 3). Since other retinal cell types in addition to HCs label for Isl 1 [33], we inferred the birth-date of Isl1+ HCs by analysing the HCs expressing Prox1 but not Lim1.

Our data demonstrated that the $\mathrm{HC}$ population in the central retina (Prox1+ HCs, Fig. 2 light grey bars) was born between E3 and E6, in accordance with previous observations [1]. Furthermore, the birth of Lim1+ HCs peaked between E3 to E4 (Fig. 2, dark grey bars), whereas the birth of Prox1+, Lim1-negative HCs (deduced to be the same as the Isl1+ HCs) peaked between E4 to E5 (Fig 2, solid black line).

\section{Lim I is expressed by axon-bearing and IsII by axon-less HCs}

We investigated how the Lim 1 and Isl1 expressing HC subgroups corresponded to the three HC subtypes previously identified by morphology [13]. Post-hatch day 7 (P7) retinas were analysed using confocal microscopy with antibodies against the known HC markers calretinin,
GABA and TrkA [35-37] in relation to Lim1 and Isl1 expression. P7 retina was chosen since the morphology of all three HC subtypes were difficult to assess at earlier stages using immunohistochemistry.

Calretinin and Lim1 were co-expressed in HCs that had morphology similar to the brush-shaped, axon-bearing HC (compare Fig. 3A with 3E, Fig. 4D). Weak GABA labelling was detected in Lim1+ HCs (Fig. 3B, arrowhead) while intense labelling was seen in a small subset of Isl1+ HCs (Fig. 3B, arrow). This intense labelling was found in HCs with morphology similar to the axon-less stellate $\mathrm{HC}$ (compare Fig. 3C with 3F). TrkA was found exclusively in the majority of Isl1+ HCs (see below) that had morphology similar to axon-less candelabrum-shaped HCs (compare Fig. 3D with 3G).

\section{GABA decreases in axon-bearing $H$ Cs from hatch to P7}

GABA is considered to be the main neurotransmitter in these inhibitory interneurons. Our results as well as others show that GABA is present in a subset of HCs [38,39]. We

\section{Birthdating of $\mathrm{HC}$ subtypes using ${ }^{3} \mathrm{H}$-Thymidine}

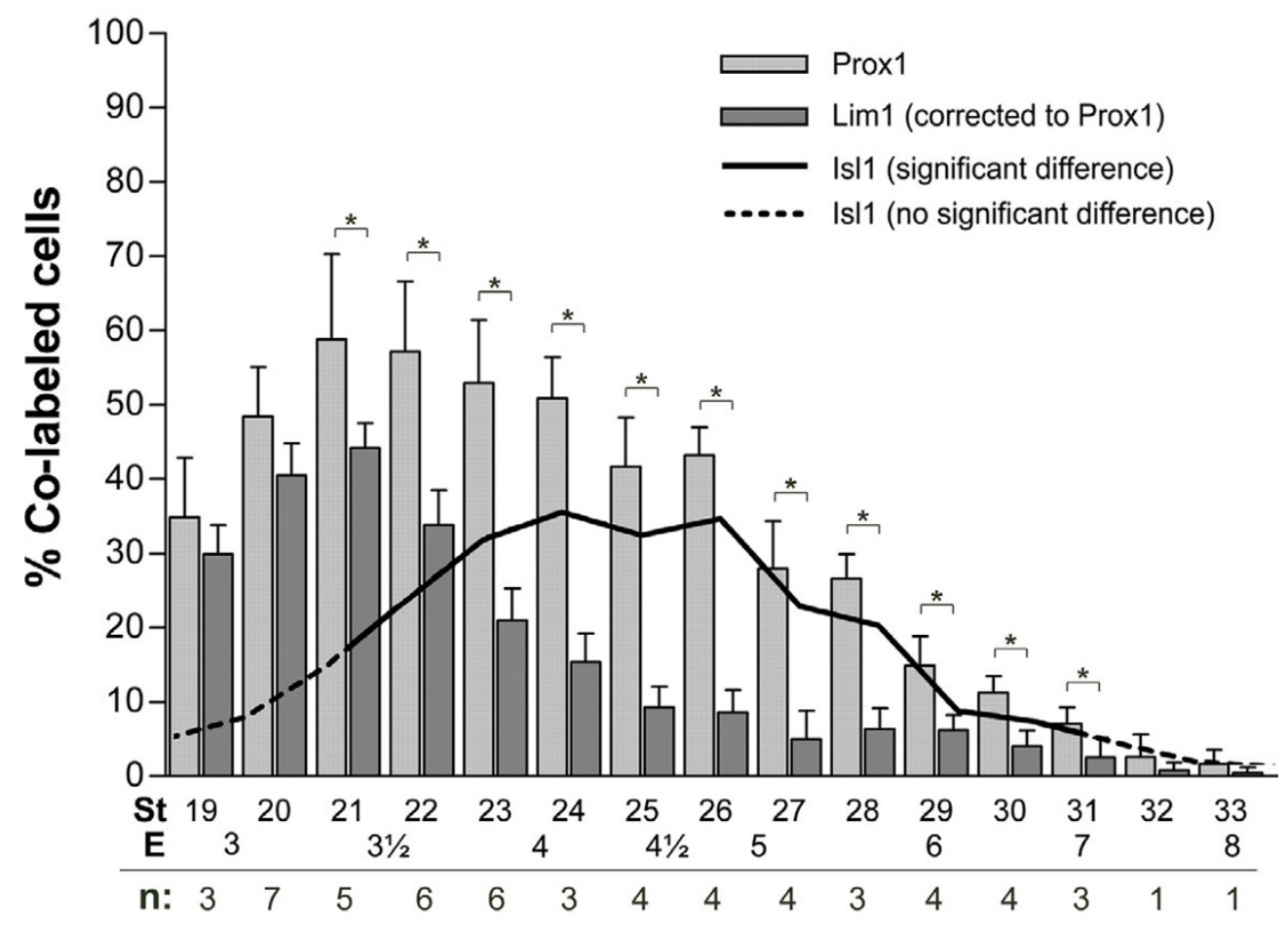

Figure 2

Lim I and IsI I horizontal cell subgroups have different birth-dates. Fractions of HCs positive for [ $\left.{ }^{3} \mathrm{H}\right]$-dT incorporation combined with either Proxl (light grey bars) or Liml (dark grey bars) analysed at st35 (expressed as \% \pm s.d., * $p<0.05$ using the Student's t-test, $n=$ number of animals that were analysed for each stage). The line indicates the difference between the ProxI and Lim I [ $\left.{ }^{3} \mathrm{H}\right]-d T$-labelled fractions, and represents the birth curve for IsII+ HCs. Solid portion of the line corresponds to significant differences. St: stage (of [ $\left.{ }^{3} \mathrm{H}\right]-d \mathrm{dT}$ injection), E: embryonic day. 

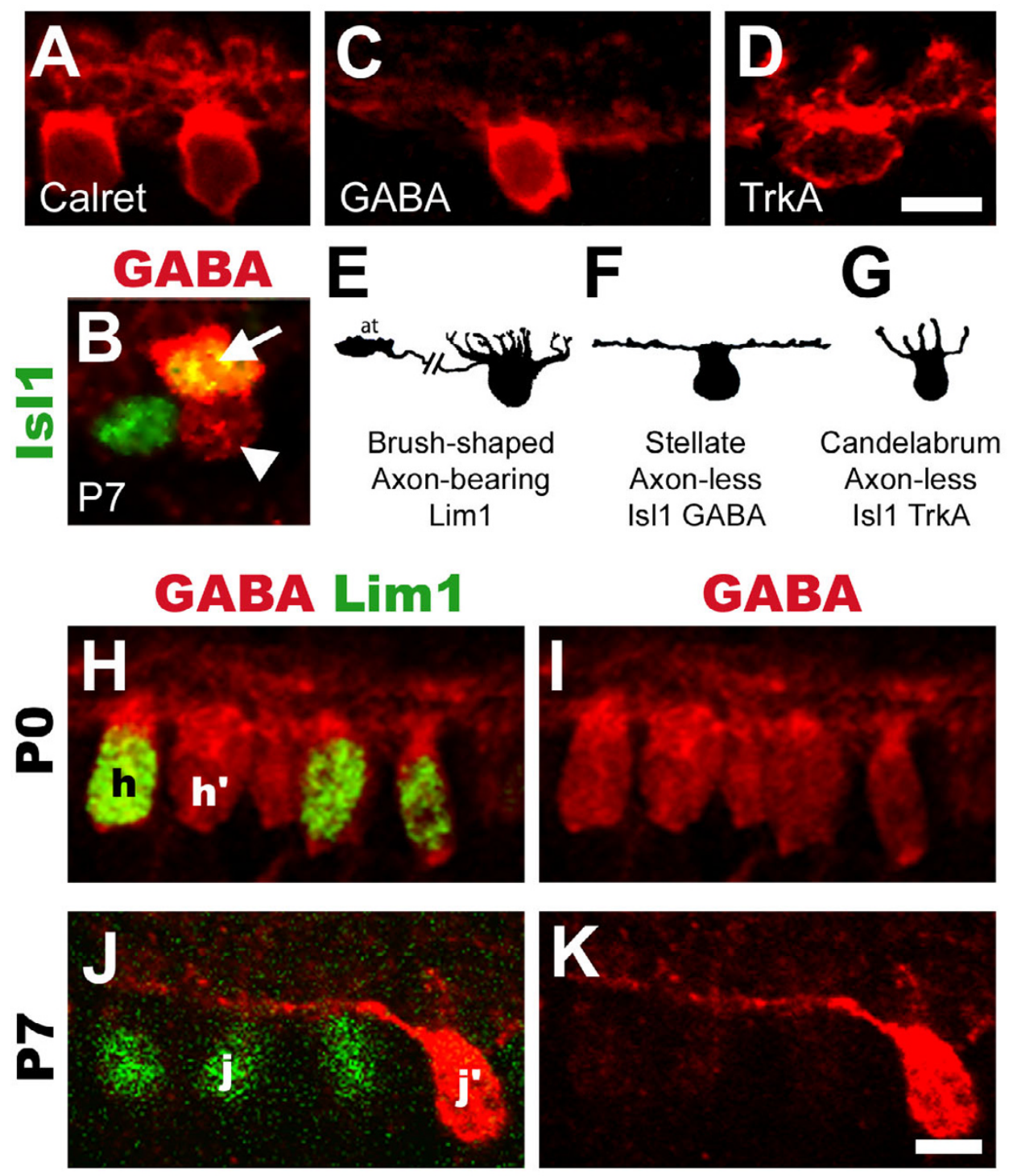

\section{Figure 3}

Confocal analysis of horizontal cell morphology and changes in GABA expression levels after hatch. (A): Axonbearing, brush-shaped HCs visualised by calretinin. (B): Flat-mounted P7 retina. GABA antibodies (red) label a fraction of Isl I+ HCs intensely (green, arrow, co-expression is yellow), and label Liml + HCs to a lesser extent (arrowhead). (C): Axon-less stellate HCs visualized by intense GABA labelling. (D): Axon-less candelabrum-shaped HCs visualised by TrkA. (E-G): Morphology of chick HCs as they appear in Gallego, 1986 [6] with names and molecular attributes denoted below. $(\mathrm{H}-\mathrm{K})$ : $\mathrm{P0}(\mathrm{H}-\mathrm{I})$ and P7 (J-K) HCs labelled for GABA (H-K, red) and Lim I (H and J, green). Uniform GABA levels are found in both Lim I + and Lim IHCs at PO (compare h with h') whereas Lim l+ HCs express low levels of GABA at P7 (compare j with j'). Scale bars are $5 \mu$ m (valid for A-D and $\mathrm{H}-\mathrm{K}$ ).

compared GABA labelling in HCs from st44 (E18), P0, P4 and P7 chicks. At st44 (not shown) and P0, GABA labelling was uniform in both Lim $1+$ and Isl1+ HCs (compare Fig. 3H-I, h and h') while at P4, a difference was notable (not shown). At P7 GABA antibodies just weakly labelled Lim1+ HCs whereas a subset of Lim1-negative HCs was strongly labelled by GABA (Fig. 3J-K, $j$ and $j$ '). In summary, GABA levels gradually change in two of the sub- types after hatching with high levels remaining in stellate Isl1+ HCs, whereas GABA-levels in axon-bearing HCs decrease.

\section{Horizontal cell subtype population sizes}

Horizontal cells from newly hatched P0 chick retinas were labelled using combinations of antibodies directed against Lim1, Isl1, Ap2 $\alpha$, Prox1, Pax6, GABA, calretinin 
and TrkA. All markers except Isl 1 and Ap2 $\alpha$ are previously well established HC markers $[18,34,36,37,40,41]$. In the P0 chick retina, Prox 1 and Pax 6 antibodies labelled all HCs. Consistent with their expression at st35, Lim1 and Isl1 did not overlap (not shown). Lim1 and Isl1 were found in fractions of Prox1, Pax6 and GABA labelled HCs (Fig. 4A-C, F-H). Calretinin was exclusively expressed in Lim1+ HCs (compare Fig. 4D with 4I) and TrkA was expressed in a fraction of Isl $1+\mathrm{HCs}$ (compare Fig. 4E with 4J). GABA and TrkA labelling did not overlap (not shown). Ap $2 \alpha$ was expressed in all axon-bearing and some axon-less HCs (Fig. 4K-O). At P0, Ap2 $\alpha$ was expressed in the majority of GABAergic HCs (Fig. 4M), in all calretinin+ HCs (Fig. 4N), but not in TrkA+ HCs (Fig. $4 \mathrm{O})$.

We quantified the fractions of cells single- or double-positive for these markers in the central retina (in direct proximity to the optic nerve exit), and found that at P0, 50\% of all HCs expressed either Lim1 or Isl1, Ap2 $\alpha$ was expressed in $56 \%$ of all HCs, and GABA and TrkA was expressed by $60 \%$ and $40 \%$ of all HCs, respectively (Fig. $4 \mathrm{P}-\mathrm{T}$ ). About $20 \%$ of the axon-less (Isl1+) HCs were labelled for GABA, and the remaining Isl1+ cells for TrkA (Fig. 4Q). Of all HCs expressing GABA at P0, 80\% were axon-bearing (Lim1+) HCs, whereas the remaining 20\% were of the axon-less stellate HC type (Fig. 4R). Quantification with respect to calretinin confirmed the previous observations of calretinin expression in axon-bearing HCs (Fig. 3A and 4S).

Our data reveal the existence of two complementary divisions of the HC population where Lim 1 and Isl 1 split the HC population 50/50, and GABA and TrkA split the population 60/40. Combined, these divide the HC population into three distinct groups where axon-bearing Lim1+ HCs constitute 50\%, axon-less stellate HCs expressing Isl 1 and GABA constitute $10 \%$ and axon-less candelabrum HCs expressing Isl 1 and TrkA constitute $40 \%$ of the HC population (Figs $4 \mathrm{~T}-\mathrm{U}$, see also $3 \mathrm{E}-\mathrm{G}$ ).

\section{Apoptosis does not affect the Prox I+ HC population}

To investigate whether apoptosis sculpted the relative proportions of HC subtypes during early retinal development, we performed TUNEL staining combined with Prox1 antibody labelling in all developmental stages ranging from st20 to st 36 as well as in selected later embryonic and post-hatch stages. We were unable to detect TUNEL stained Prox $1+$ cells in any of the early stages we investigated (Fig. 5A-F). At later retinal stages, a double-stained cell could occasionally be found in the extreme peripheral retina, but not in the early developing retina nor in the central retina. TUNEL and Isl1+ double-labelled cells belonging to other neuronal populations were observed (not shown).
The onset of Lim I expression is preceded by a drastic wave-like decrease of endogenous follistatin expression Previous results have shown that over-expression of follistatin in the developing retina results in ectopic cells expressing Prox1 [28]. This observation prompted us to further investigate the HC generation with respect to follistatin. We analyzed the follistatin mRNA expression in total retina from st 14 to st 45 embryos using qRT-PCR. The levels were normalized to the house-keeping genes $\beta$-actin and TATA-box binding protein. By far, the highest levels of follistatin mRNA were in the optic cup and early eye (Fig. 6A, note logarithmic graph scale, see also Additional file $3)$. The mRNA levels dropped sharply until reaching relatively very low levels between st 23 and st 30 (Fig. 6B, note linear graph scale). The levels increased again after st 35 . For comparison we analyzed the related factor follistatinlike 1, which in contrast to follistatin was not developmentally regulated (Fig. 6A-B). The drop in follistatin mRNA levels between stages 18 and 25 (Fig. 6C and 6D) coincides with the birth of Lim1+ HCs (Fig. 2).

Lim 1 expression commences in the central retina at st1920 [33] and extends peripherally as development progresses. At the early developmental stages, follistatin immunoreactivity was strong in retina, lens and pigment epithelium. With increasing age, a central to peripheral gradient of different strengths of follistatin immunoreactivity in the retina became progressively more obvious, with the strongest immunoreactivity levels located in the periphery (Fig. 6C and 6D, black arrows). The onset of Lim1 expression followed close behind the decrease of follistatin immunoreactivity as it moved towards the periphery (Fig. 6C and 6D). As development progressed (E4-E8), the endogenous expression of follistatin in the central retina became restricted to cells located in the putative GCL, whereas the expression in the central-outer retina gradually waned (not shown). By st34 (E8), follistatin immunoreactivity was restricted to the GCL and to cells located on the inner rim of the INL (see Additional file 2).

\section{Injection of follistatin at E3 decreases the number of newly generated Lim I+ cells}

As retinal development progressed in a central to peripheral fashion, we observed that decreasing levels of follistatin immunoreactivity preceded the onset and expansion of Lim 1 expression. This inverse correlation between HC generation and high follistatin levels suggested that follistatin overexposure may interfere with the generation of Lim $1+$ cells. We injected st 21 , st 22 and st 23 embryos with follistatin or vehicle and analysed the number of Lim $1+$ cells in the central retina $22 \mathrm{~h}$ after the injection. The follistatin bolus injection caused a significant 20-25\% reduction in the number of $\operatorname{Lim} 1+$ cells per $\mathrm{mm}^{2}$ retina in 

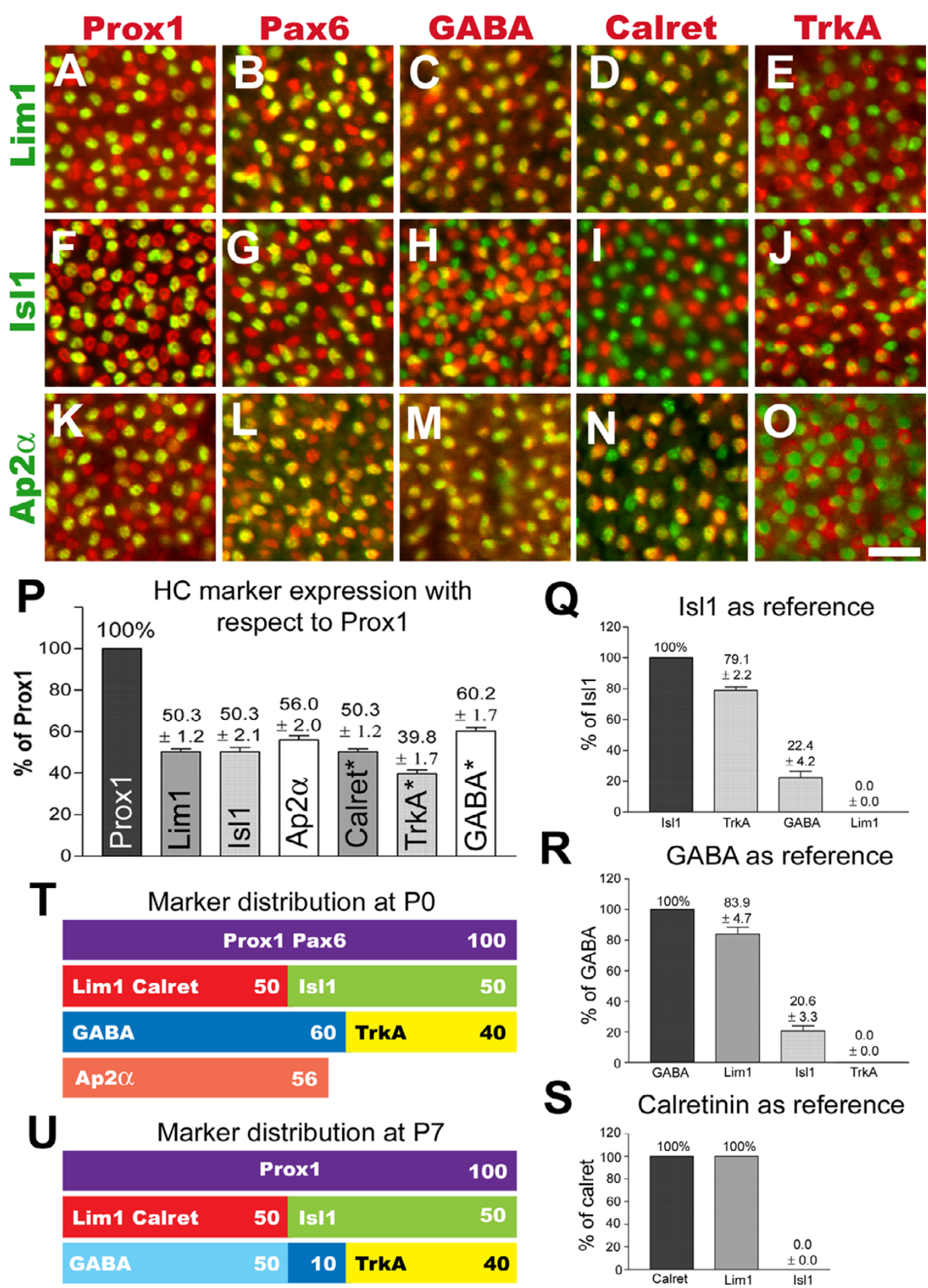

Figure 4

Horizontal cell subtypes express different sets of markers. (A-O): The horizontal cell layer of flat-mounted $P 0$ retinas labelled with LimI (A-E, green), IsII (F-J, green) and Ap2 $\alpha$ (K-O, green), combined with ProxI (A, F, K, red), Pax6 (B, G, L, red), GABA (C, H, M, red), calretinin ( $D, I, N$, red) and TrkA (E, J, O, red). Double positive cells appear yellow. (P-S): Calculated fractions (expressed as $\% \pm$ s.d., $n$ animals $=3$ ) of $\mathrm{HCs}$ co-expressing various markers with respect to ProxI $(\mathrm{P})$, IsII $(\mathrm{Q})$, GABA (R) and calretinin (S). Asterisks in $P$ denote that these fractions were calculated using known fractions of other markers. (T-U): Distribution of HC markers at P0 and P7. Scale bar is $20 \mu \mathrm{m}$ (valid for A-O). 


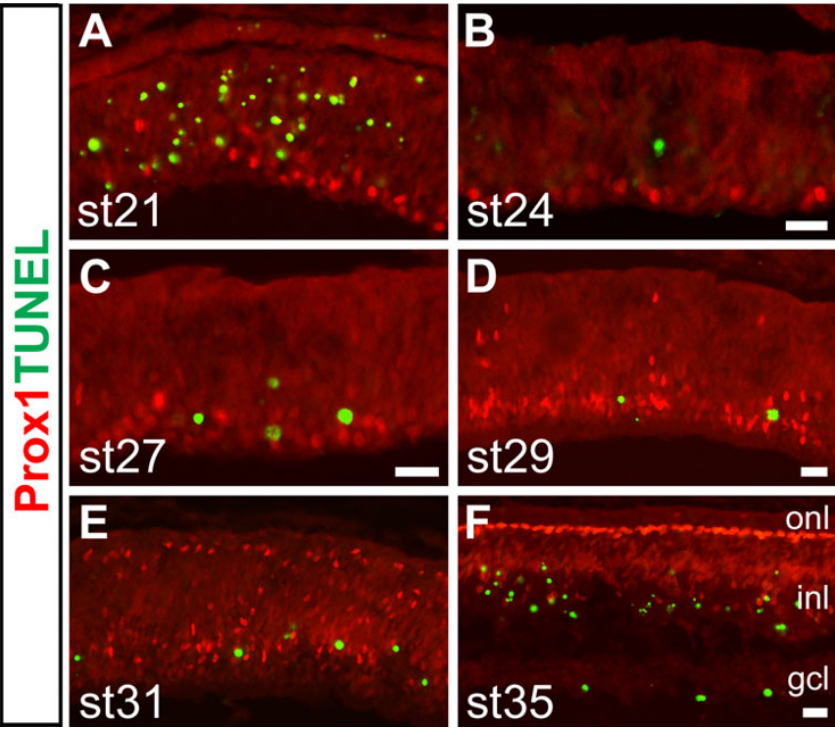

Figure 5

Horizontal cells are not affected by apoptosis. (A-F): Stage 2I (A), 24 (B), 27 (C), 29 (D), 3I (E) and 35 (F) retinas stained for TUNEL (green) and ProxI (red) reveal no overlap between the two signals. Scale bars: $20 \mu \mathrm{m}$ (B and F are valid for $A-B$ and $E-F)$.

all stages tested ( $\mathrm{p}<0.05$, Mann-Whitney test, Fig. $6 \mathrm{E}$ and $6 \mathrm{~F}-\mathrm{G}$, see also Additional file 3 ).

The main target for the inhibitory action of follistatin is activin $[31,42]$, which is expressed in the developing retina [24] and is known to decrease cell proliferation in many cell types and tissues [42]. We therefore hypothesised that the reduction of newly generated Lim $1+$ cells by the added follistatin, was an effect on the Lim1-generating progenitor cells. The inhibitory action of follistatin would then keep the progenitor cells proliferating and thus delaying cells from exiting the cell cycle and turning on Lim1 expression. This would lead to fewer newly generated Lim1+ cells compared to controls. To test this we added BrdU $5 \mathrm{~h}$ after either follistatin or activin injections to mark cells passing through S-phase. The number of BrdU cells was analyzed after a total of $22 \mathrm{~h}$. The activin injections caused a robust decrease in BrdU incorporation compared to controls (Fig. 7A-C, see also Additional file 3) while the follistatin injections did not lead to any conclusive changes (data not shown). This indicates that activin treatment caused either an overall decreased proliferation rate or caused retinal progenitor cells (RPCs) to undergo premature cell cycle withdrawal. This finding indirectly support the hypothesis that the bolus dose of follistatin delays the onset of Lim 1 expression by keeping progenitor cells in a proliferative state.
Injection of follistatin at E3 affects retinal histology at E9 Effects on HCs can definitely be monitored first at st35 (E9), the time when both Lim1+ and Isl1+ HCs have migrated to the HCL. We performed a series of injections of follistatin into eyes of embryos ranging from st18-31. Analyses of Prox1, Lim1 and Isl1 immunoreactivity were then carried out at st35 (E9). We found that the structure of the inner plexiform layer was frequently distorted in embryos injected at early stages up to st 24 , but that no obvious phenotype could be observed from st 26 and beyond (not shown). The typical follistatin-histology in our experiment at st35 is consistent with Moreira and Adler's observations [28], and was characterized by a thinner inner plexiform layer (Fig. 8, compare A with B and C) and ectopic Prox $1+$ cells either scattered or arranged in columns spanning the GCL and/or INL (Fig. 8B and 8E, brackets). This phenotype served as our criterion to determine if a retinal region had been affected by follistatin, and images from such regions were acquired and used for further analysis.

\section{Follistatin produces ectopic horizontal cells that migrate back to the $\mathrm{HCL}$}

The expression of Prox1, although at ectopic locations in the st35 (E9) retina, hinted that the cells were HCs. We wanted to know whether the ectopic Prox1+ cells were in fact HCs and investigated if they in addition to Prox1 expressed Lim1 or Isl1. Embryos were analysed with respect to HC development at st35. Some of the retinas were analysed one day later at st36 (E10). This relatively long post-injection time of 6-7 days was chosen in order to ensure the correct identification and quantification of HC subtypes, based both on their marker expression and localization in the retina.

Double immunohistochemistry for Prox1, Lim1 and Isl1 (Fig. 8A-E) showed that the ectopic Prox1 cells seen at st35 expressed either Lim 1 or Isl1, indicating that ectopic Prox $1+$ cells were bona fide HCs. Consistent with our previous results, we did not observe Lim1 and Isl1 co-expression in control or follistatin-treated retinas (not shown). The ectopic cells in the st35 retina were predominantly of the Prox1, Isl1 double positive HC subtype (Fig. 8B and $8 \mathrm{E}$, white arrows) and only a fraction of the ectopic Prox 1+ cells expressed Lim1 (Fig. 8E, black arrow). One day later at st36/E10, ectopic HCs could not be found (Fig. 8C). Since the total number of cells double-positive for Prox 1 and Lim 1 or Prox 1 and Isl1 (i.e. the ectopic cells and the ones present in the HCL) were similar in st35 and st36 retinas (data not shown), and apoptosis was not detected in normal or ectopic Prox1+ cells as shown by TUNEL (Fig. 8F), it was concluded that the st35 ectopic HCs had migrated back to the HCL at st36 (compare Fig. $8 \mathrm{~B}$ and $8 \mathrm{C}$, single and double asterisks) following a normal although delayed migration route. 

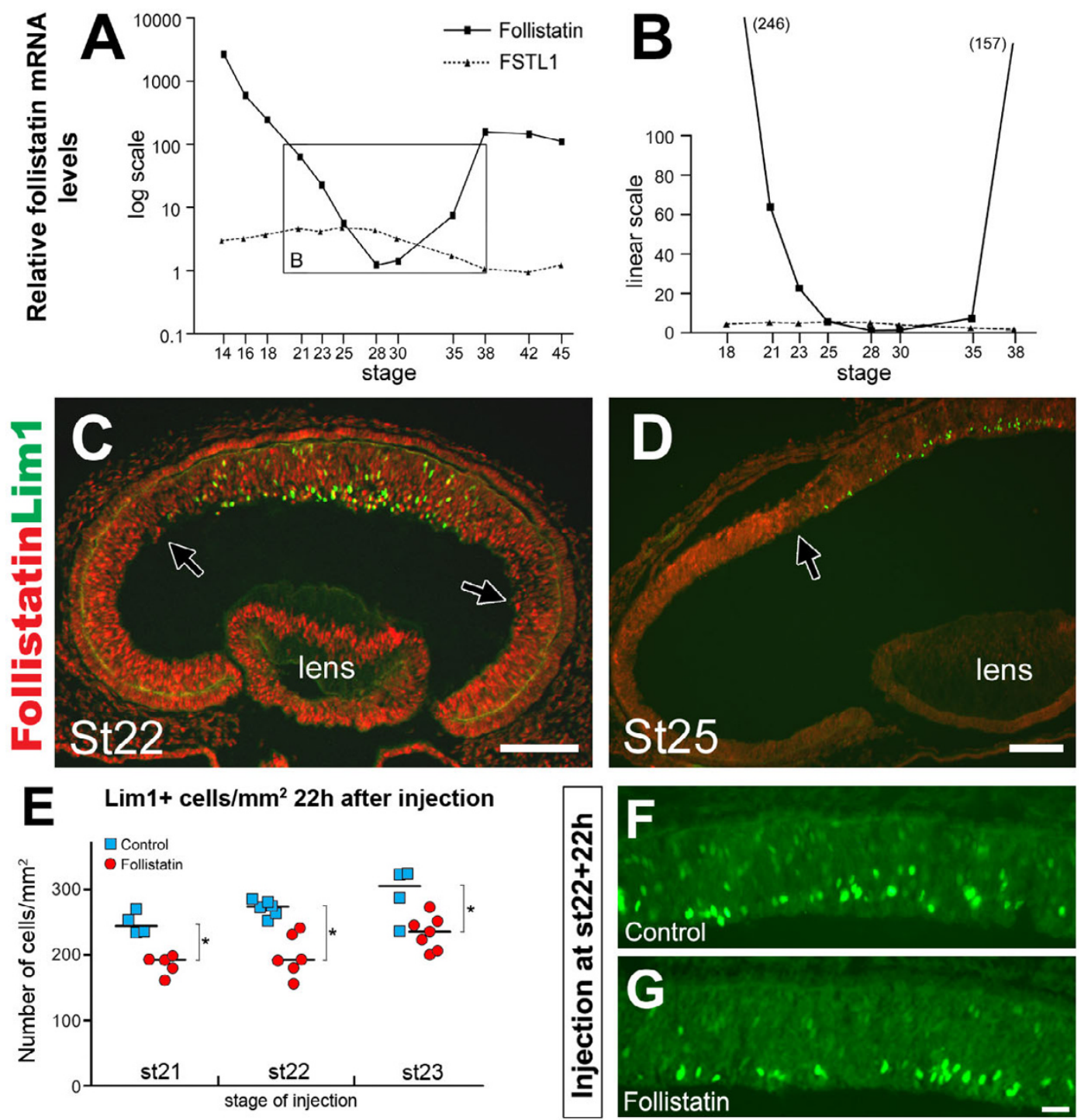

\section{Figure 6}

Decreased follistatin expression coincides with the generation of horizontal cells. (A-B): Follistatin (solid line) and follistatinlike I (FSTLI, dashed line) mRNA levels during retinal development relative the lowest value respectively which is set to I (follistatin: I = st28; FSTLI: I = st42). The X-axis denotes the embryonic stages analysed and the $Y$-axis denotes the relative mRNA levels in log scale (A) or linear scale (B). Numbers in parenthesis in B denote the relative follistatin mRNA level-value at stl 8 and 38, respectively. (C-D): Follistatin immunoreactivity (red) in the developing retina at st22 (C) and st25 (D) reveal a central-to-peripheral gradient of follistatin expression. Highest levels are expressed peripherally and sharp boundaries between high and low expression are evident (black arrows). The onset of Liml expression (green) is trailing the wave-front of decreasing follistatin expression. (E): $22 \mathrm{~h}$ after follistatin treatment at st 2 I, st 22 or st 23 , the number of Lim I+ cells decreases by approximately $20-25 \%$. Lim I + cells were counted in $20 \times$ visual fields and expressed as Lim I+ cells $/ \mathrm{mm}^{2}$ retina. Blue squares indicate the means of individual control treated animals and red circles indicate the means of individual follistatin-treated animals. The medians are indicated by a black line, ${ }^{*}$ denote significant differences $(p<0.05, M a n n-$ Whitney test). F-G: Lim I expression (green) in central retina $22 \mathrm{~h}$ after control (F) or follistatin (G) treatment in st22 embryos. Scale bars are $100 \mu \mathrm{m}(\mathrm{C}-\mathrm{D})$, and $20 \mu \mathrm{m}$ in $\mathrm{G}$ (valid for $\mathrm{F}-\mathrm{G})$.

\section{Injections of follistatin at E3 increase the number of HCs at E9}

When analysing regions containing ectopic Prox $1+$ cells it appeared as if the number of Prox1+ HCs had increased. This was in contrast to the results obtained for Lim $1+$ cells $22 \mathrm{~h}$ after follistatin administration. We injected follista- tin in a series of embryos at the phase of HC generation. As shown by the HC birth-dating experiments (Fig. 2), st20 and st23 correspond to the initial phases of the generation of the two HCs populations, respectively. This period also corresponds to when the endogenous follistatin levels drop (Fig. 6A-B). Controls were injected with 

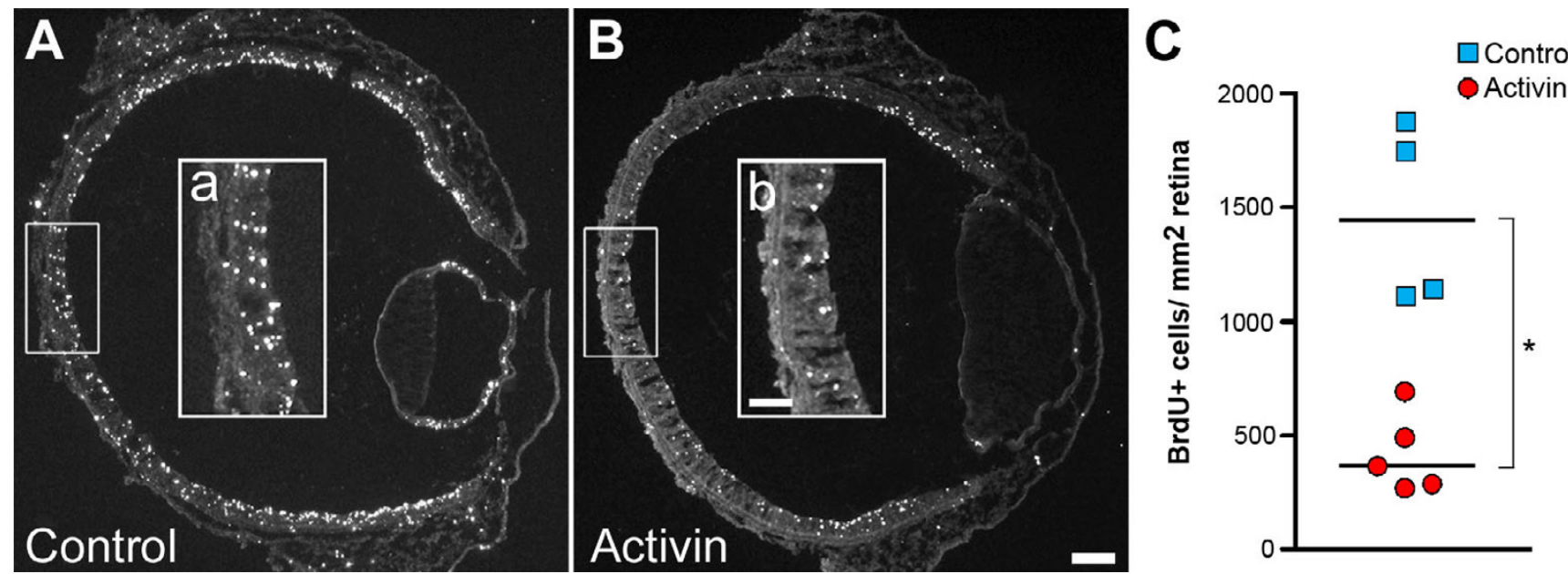

Figure 7

Decreased BrdU incorporation following activin treatment. BrdU incorporation was assayed in st23 activin treated retinas $(A)$ and control injected retinas (B) using immunohistochemistry. After activin treatment, BrdU incorporation was markedly reduced compared to controls (compare a and $b$ ). $(C)$ : When quantified, this reduction was found to be significant $(*$ $\mathrm{p}<0.05$, Mann-Whitney test). Blue squares indicate the means of individual control treated animals and red circles indicate the means of individual activin-treated animals. The medians are indicated by a black line. Scale bars B and b are $100 \mu \mathrm{m}$ and $50 \mu \mathrm{m}$, respectively (valid for $A-B$ and $a-b)$.

vehicle at st 21 or st 23 . We counted cells double-positive for Prox1 and Lim1, and Prox1 and Isl1 at st35, in retinas treated with follistatin at st20,21, 22 or st23 and each stage was then compared individually with controls treated with vehicle at st 21 or st 23 .

If the st20 treatment preferentially had effects on the early Lim 1 population and not on the later Isl1 population, while the st 23 treatment had effects on the late population, it could be hypothesized that the Lim1 and Isl1 HC subtypes are generated from separate progenitor cells. Conversely, if the early follistatin treatment also had effects on the late population it is likely that both subtypes are generated from a common pool of progenitor cells that is affected by the follistatin inhibition and expanded.

We found that follistatin treatment at all 4 stages caused a significant increase in the total number of HCs (Prox1+) as well as significant increases in both the number of Lim1+ and Isl1+ HC subtypes compared to controls (Fig. $8 \mathrm{G}-\mathrm{I}$, see also Additional file 3 ). With respect to the number of Lim 1+ or Isl1+ cells in follistatin-treated animals, we found no difference between the early and late injection stages (Fig. 8G-I). Over all, the increase in the total number of Prox $1+$ cells was approximately $30 \%$, for Lim1, Prox1 double positive cells approximately 40\%, and for Isl1, Prox1 double positive cells approximately $50 \%$ (means of the 4 stages, see also Additional file 3 ). Thus, our data showed that follistatin overexposure at st $20,21,22$ or st 23 caused an over-production of both the
Lim $1+$ and the Isl1+ HC subtypes when analyzed at st35, regardless of the stage of treatment.

\section{Follistatin treatment and the effects on other retinal cell types}

We analysed whether follistatin treatment at st 23 influenced the generation of cell types other than HCs by quantifying the number of cells carrying markers against photoreceptors (Lim3, Isl1/2), amacrine cells (Ap2 $\alpha$ ), bipolar cells (Lim3, Isl1) and ganglion cells (Isl1) in st35 retinas [33]. We did not detect any differences in the number of immunoreactive cells in the outer nuclear layer after follistatin treatment using Lim3 (Fig. 9A-B) or Isl1/ 2 antibodies (Fig. 8A-C and 9E-F). The cells in the outer nuclear layer labelled by the Isl1/2 antibody most likely correspond to Isl2+ cells, since labelling with another Isl1 specific antibody did not produce immunoreactivity in these cells (not shown). In the INL, the bipolar cell population marked by Lim3 and Isl1 (Fig. 9A-B and 9E-F), and the amacrine cell population marked by Ap $2 \alpha$ (Fig. 9CD) were not affected by the follistatin treatment (Fig. 9HI). In the GCL we did not detect any significant differences in the number of Isl1+ cells compared to controls (Fig. $8 \mathrm{~A}-\mathrm{C}$ and $9 \mathrm{E}-\mathrm{F}, \mathrm{I})$. Noteworthy is that due to loss of inner plexiform layer thickness following follistatin treatment, we could not distinguish Isl1+ ganglion cells from Isl1+ amacrine cells normally present in the inner nuclear- and plexiform layers (compare Fig. 8A and 8B). Therefore, the Isl1 cell-counts in figure 9I include both these cell types. These data are also summarized in Additional file 3. These 
Control
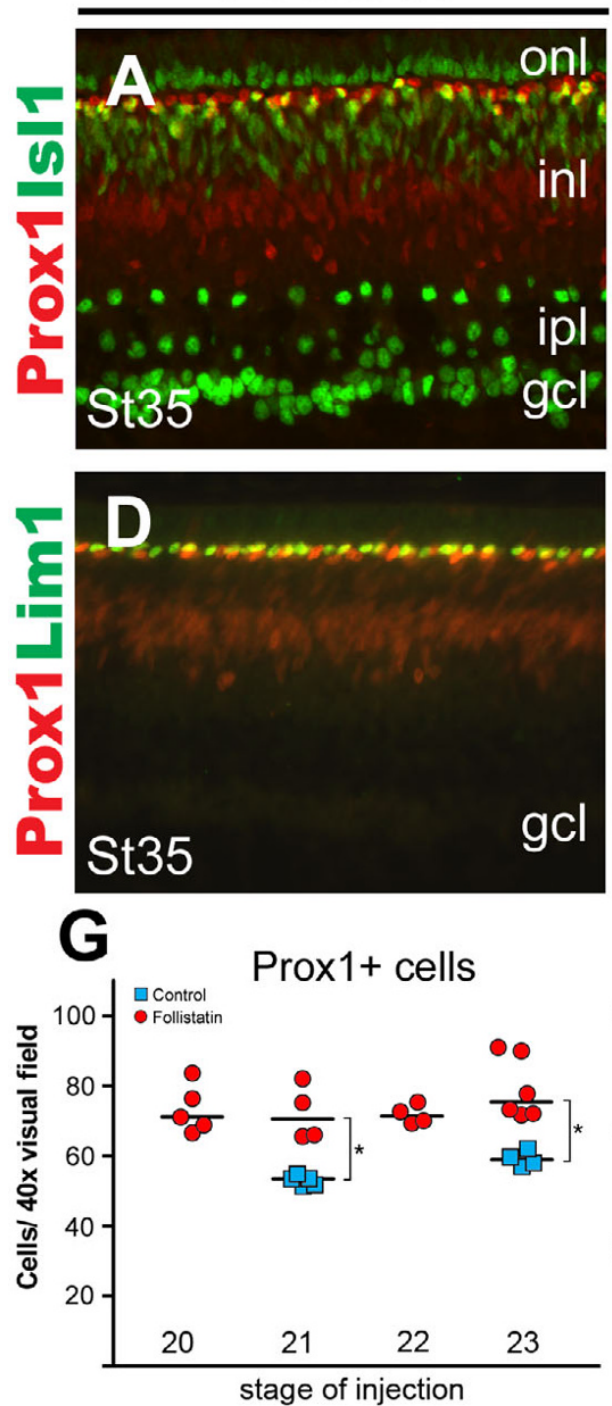

Follistatin
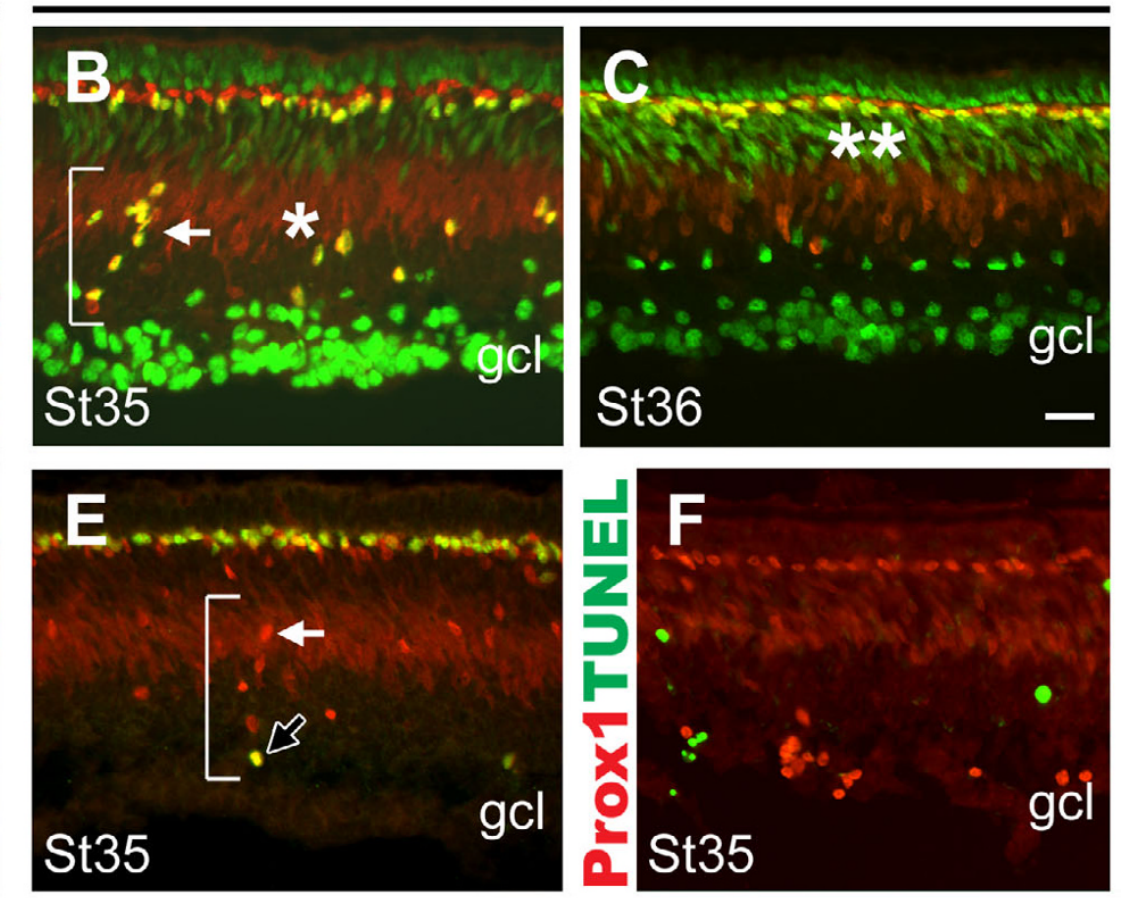

H
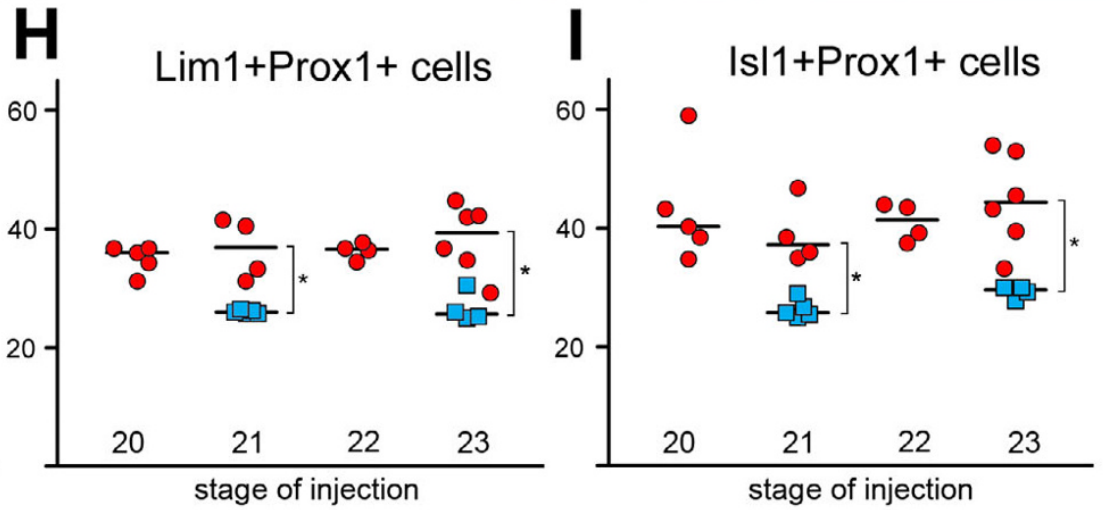

Figure 8

Follistatin treatment at E3 increase the number of horizontal cells at E9. (A-F): Retinal cross-sections stained for ProxI (A-F, red) combined with IsII (A-C, green), Lim I (D-E, green) or TUNEL (F, green). Co-labelled cells appear yellow. Compared to st35 control retinas $(A$ and $D)$ follistatin treated retinas $(B, C$ and $E$ ) have ectopic Prox I + cells in the inner retina which are often arranged in columns (B and E, brackets). These ectopic ProxI+ cells are primarily of the IsII+ HC subtype (white arrows), although some are Lim I+ (E, black arrow). (C): At st36, ectopic HCs have migrated to the $\mathrm{HCL}$ (compare double asterisks with single asterisk in B). (F): St35 Proxl and TUNEL-staining reveal no overlap. (G-I): Quantification at st35 of the number of HCs in 40x visual fields following follistatin treatment at various E3-stages. Blue squares indicate the means of individual control treated animals and red circles indicate the means of individual follistatin-treated animals. The medians are indicated by a black line. Follistatin causes a significant increase in the number of $\mathrm{HCs}(\mathrm{ProxI}+)$ and $\mathrm{HC}$ subtypes (Lim+ or Isl I+ HCs) at all stages, compared to controls (*p $<0.05$, Mann-Whitney test, see also Additional file 3 ). Scale bar is $20 \mu \mathrm{m}$ (valid for A-F).

data suggest that under these experimental conditions, HCs is the only cell type that is affected by the follistatin treatment at st23.

\section{Discussion}

\section{Horizontal cell subtypes and their maturation}

In this work we have demonstrated that HCs are generated as two equally large and distinct subgroups during early retinogenesis. One subgroup, corresponding to the axonbearing HC, expresses Lim1 whereas the other subgroup, corresponding to the axon-less HCs, expresses Isl1. The 


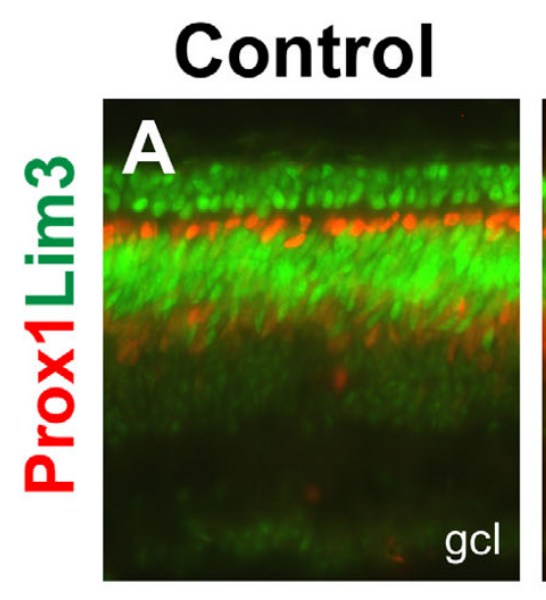

\section{Follistatin}
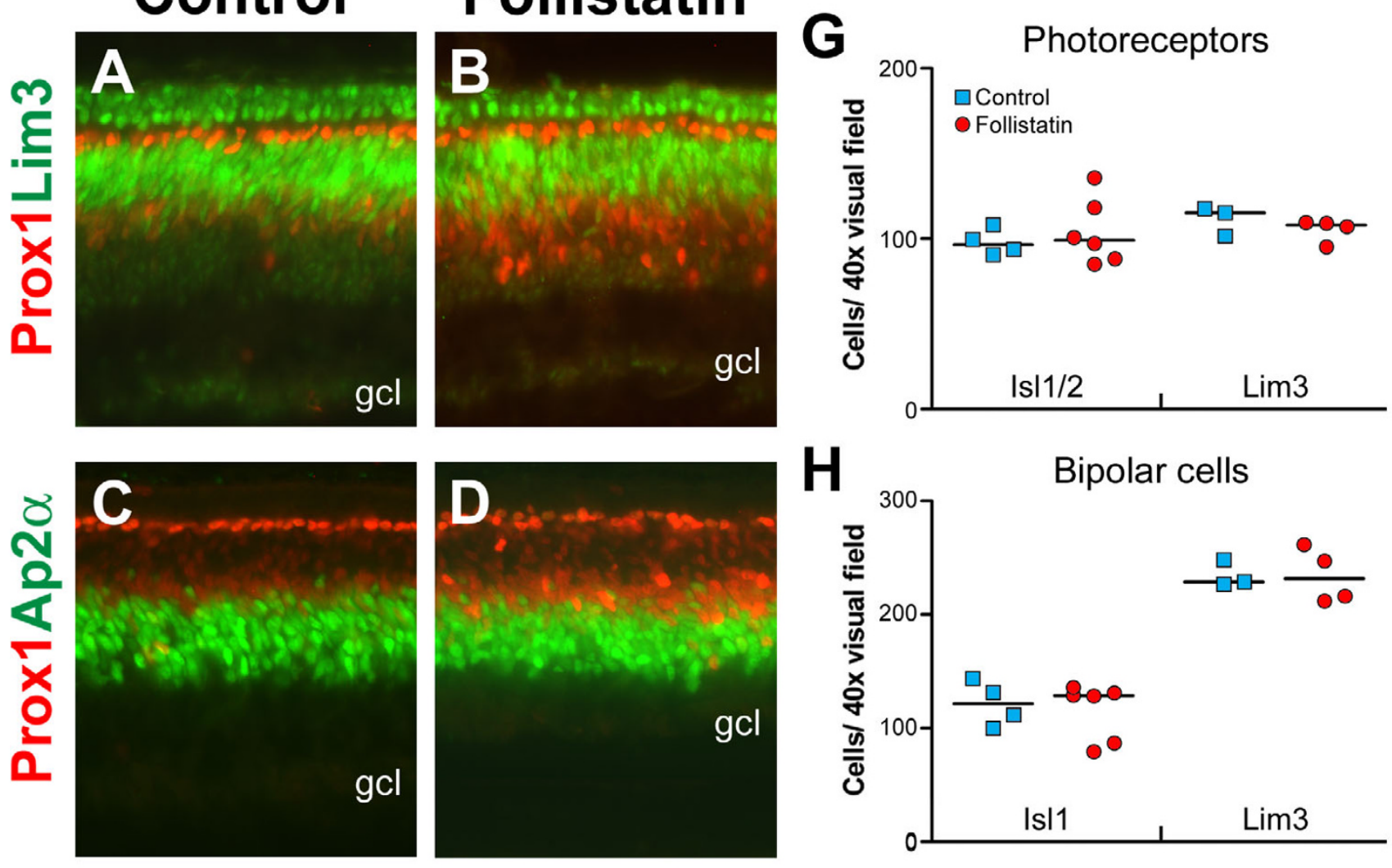

\section{$\mathrm{H}$}

\section{Bipolar cells}
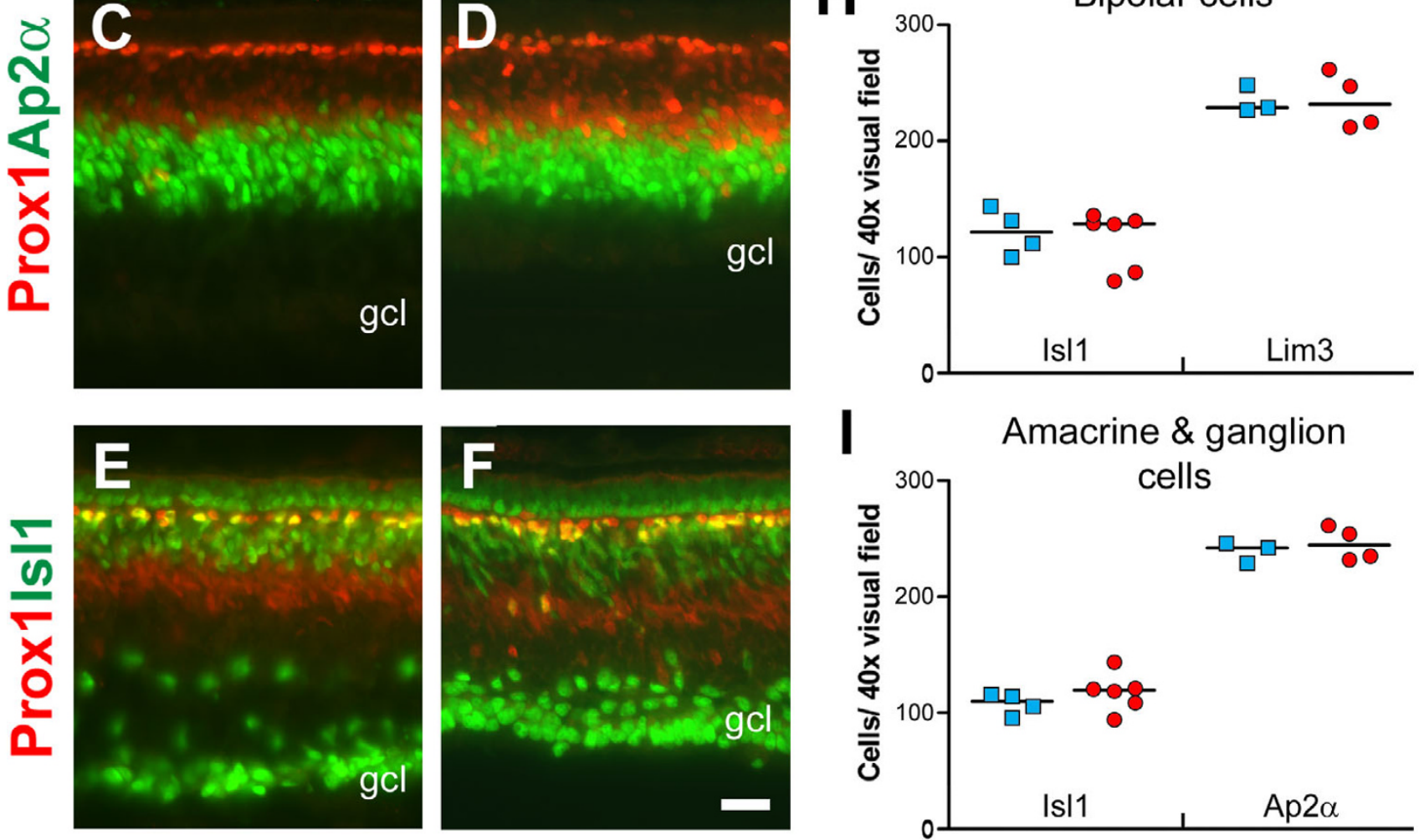

\section{Figure 9}

Effects on other cell populations following follistatin treatment. Control (A, C, and $E)$ or follistatin-treated retinas (B, D, and $F$ ) stained for ProxI (A-F, red) and Lim3 (A-B, green), Ap2 $\alpha$ (C-D, green) and Isl I (E-F, green). All injections were made at st23 and analysed at st35. With respect to the thickness of immuno-labelled bands, all markers appear grossly normal after follistatin injection. (G-I): Quantification of immuno-labelled cells in $40 \times$ visual fields. Blue squares indicate the means of individual control treated animals and red circles indicate the means of individual follistatin-treated animals. The medians are indicated by a black line. Using the above markers, no significant differences $(p<0.05$, Mann-Whitney test) were found between control or follistatin treated retinas with respect to the number of photoreceptors, bipolar cells, amacrine cells or ganglion cells. Note that the IsII+ cells quantified in $9 \mid$ include both Is I + ganglion and amacrine cells. Scale bar is $20 \mu \mathrm{m}$ (valid for A-F).

axon-less (Isl1+) HC subpopulation can be further subdivided in two HC subtypes. The Lim1 and Isl1 HC subgroups are generated and then migrate bi-directionally in the developing retina during successive periods. Moreover, we show that retinal progenitor cells that are able to generate both Lim1 and Isl1 HCs respond to follistatin overexposure at E3. The treatment results in significant increases in both Lim1 and Isl1 HC subtypes at E9. This effect is specific to HCs, and is best explained by a sustained proliferation of HC-generating progenitor cells. 
We have demonstrated two types of axon-less HCs, the stellate and candelabrum-shaped HCs that in addition to Isl1, express GABA and TrkA, respectively. The axon-bearing brush-shaped HCs express calretinin in addition to Lim1. We quantified the proportions of the HC subtypes in the central P0 chick retina and found that the axonbearing brush-shaped HC and the axon-less stellate and candelabrum-shaped HCs constituted 50\%, 10\% and $40 \%$ of the HC population, respectively. These findings are consistent with previous reports on chick HCs $[6,13,38,39,43]$. However, in slight contrast to our findings one recent report demonstrated that in P7-P21 chick retina a small fraction of Isl1+ HCs express calretinin [38], an observation that is not supported by our P0 retinal preparations and it is therefore possible that a subset of Isl1+ HCs turn on calretinin expression after hatching. The same study also identified what was classified as a fourth HC subtype based on their analysis of HC markers. A fourth HC subtype is also described in the pigeon retina based on morphological criteria [12]. Our results support the classical division of chick HCs into three main subtypes $[6,13]$ but the actual number and extent of heterogeneity in HC subtypes in the chick retina is an unsettled issue.

As the retina undergoes late maturation, synapse rearrangement and changes in the expression levels of various proteins are known to occur [44-46]. We found that GABA was initially present uniformly in all GABA-containing HCs, but that GABA levels progressively decreased in axon-bearing HCs and increased in axon-less stellate HCs after hatch. This implies that GABA has a role in adult stellate HCs but not in adult axon-bearing cells. Rather, GABA may have a transient function in the developing axonbearing HCs. This is in agreement with a role for GABA during synapse maturation when connections between HCs and photoreceptors or bipolar cells are established [47]. Other studies have reported changes in GABA levels during phenotypic maturation of HCs in rats, rabbits, guinea pigs and humans [48-51].

\section{Early development of HC subtypes}

Most classes of retinal neurons undergo cell death during development [52]. Photoreceptors and HCs are likely exceptions to this rule [53] and it has been shown that HCs do not undergo apoptosis during later stages of development $[54,55]$. We investigated apoptosis in HCs using TUNEL during early (Fig. 5) and late retinal development (not shown), but could not find evidence to suggest that the HC population size was adjusted by apoptosis. Moreover, Lim1+ HCs have been shown to migrate bi-directionally across the retina [34] and in this study we show that the Prox1, Isl1 double positive HCs followed a similar but delayed pattern, migrating approximately one day later (compare asterisks in Fig. 1C-L, Fig.
10A). Hence, we concluded that Isl1+ HCs also undergo bi-directional migration.

We investigated whether the two HC subpopulations marked by Lim 1 or Isl1 were born simultaneously or consecutively by performing a birth-dating analysis using $\left[{ }^{3} \mathrm{H}\right]-\mathrm{dT}$ incorporation. Our results revealed that although the two birth-curves overlapped, the majority of Lim1+ HCs were born between E3 and E4 whereas the majority of the HCs expressing Isl1+ were born between E4 and E5 (Fig. 2). However, since the earliest stage when Isl1+ HCs can be positively identified using Prox1 is st31 (Fig. $1 \mathrm{H}$, arrows), the lack of earlier HC subtype markers makes it difficult to state with certainty that HC progenitors that give rise to the Isl1+ HCs are in fact born into an Isl1-fate (and not born as Lim $1+$ cells). However, the birth-curve of the Isl1+ HCs is concomitant with the appearance of Prox1+, Lim1-negative cells in the retina between E5.5 and E7 [34]. These Prox1-single positive cells likely correspond to the Isl1+ HC fraction before the actual onset of Isl1 expression. Thus, the birth-dating results inferring that Isl1+ HCs undergo their last S-phase around E4-5, which is just prior to the appearance of Prox1-single positive cells at E5.5, supports a scenario where the late $\mathrm{HC}$ subgroup identity is established at the time of cell cycle withdrawal. In addition, we do not find any Isl1 and Lim 1 double labelling in HCs (Prox1+ cells) after st31. Godinho et al recently used live imaging in the zebrafish retina to show that the mitoses generating HCs occurred in the INL [56]. Combined, these data opens up the possibility that HCs in chick are generated as cells committed into distinct fates (Lim1/early or Isl1/late), and that the generation of these subgroups is temporally separated.

The results from a recent lineage study of chick HCs suggested that there was no significant difference in the birth order among three identified HC subtypes [57]. Our birth-dating experiment only considered HCs in the very central part of the retina and as the generation of HCs proceed further peripherally in the retina the temporal overlap of the generation may be larger. This may explain the discrepancy between the different results. In addition, the two waves of migration to the HCL also imply a consecutive generation of the subtypes.

The separate birth-dates and migration periods reveal the existence of temporal windows during which $\mathrm{HC}$ precursors can acquire different fates. For instance, the generation of stellate HCs could result from a combination of instructive signals acting at overlapping time points. Stellate HCs could be generated during an overlap of: a) a decreasing signal instructing early born HCs to express Ap $2 \alpha$ and GABA, and b) an increasing signal instructing late-born HCs to express Isl1. The $6-10 \%$ abundance of Ap $2 \alpha$ and GABA expression in the stellate HCs may sug- 
A Generation and migration of Lim 1 and IsI1 HC subtypes

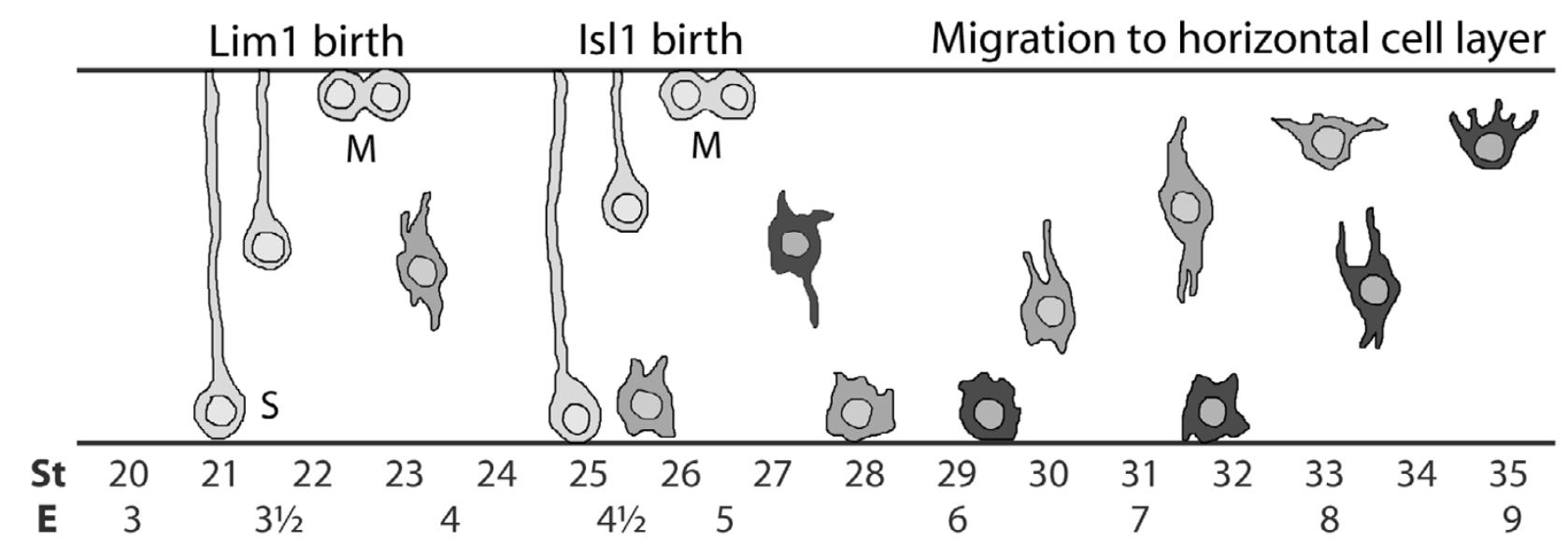

B Model for follistatin-mediated regulation of RPC proliferation
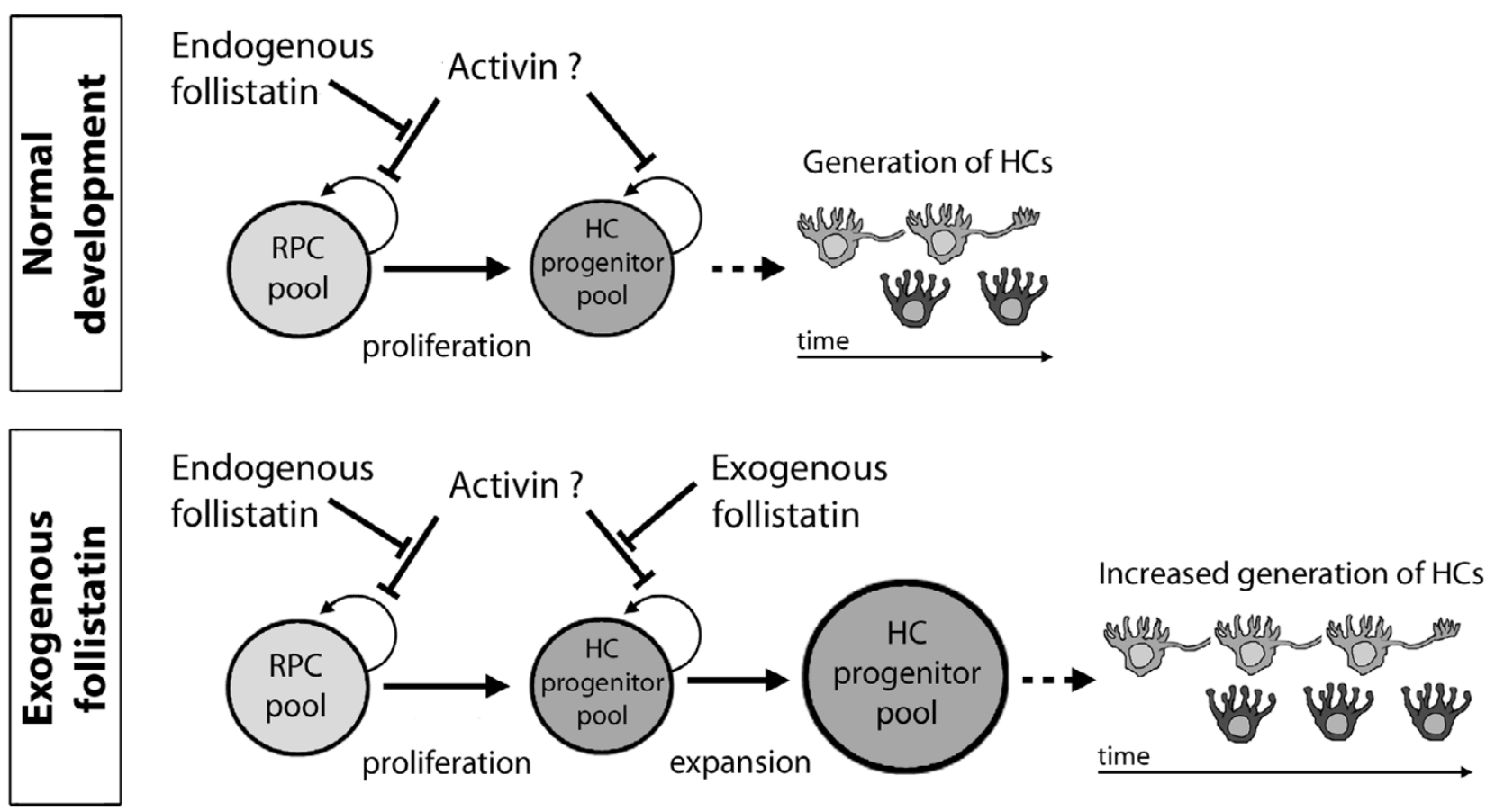

Figure 10

Schematic summary of horizontal cell development. (A): Schematic figure of the generation and migration of Lim I+ and IsII+ HCs. S and M denote stages of the cell cycle. Position of M-phase cells is according to the classical view, however see also Godinho et al [56]. (B): Proposed model for the effects of follistatin on RPCs during retinogenesis. During normal development, high follistatin levels stimulate the proliferation of RPCs by preventing e.g. activin (or related factors) to decrease or inhibit proliferation. As follistatin decreases over time, RPCs specialize to generate e.g. HC progenitors. Under the influence of exogenous follistatin, again preventing activin (or related factors) from controlling cell cycle withdrawal, proliferation in the HC generating progenitor pool is stimulated and therefore, more HCs than normal are eventually generated.

gest such a mechanism (Fig. 4T). In this scenario, later born Isl1+ HCs (i.e. the TrkA+ candelabrum HCs) would encounter only the second signal and develop along a third route. These potential signals remain to be character- ized and may be either extrinsic, intrinsic or both. The signals seem not to be of a character that could be inhibited by follistatin since the subpopulations were not differentially affected by this treatment. 


\section{Follistatin promotes the proliferation of HC-generating progenitor cells}

In the developing retina extrinsic signals, exemplified by the TGF $\beta /$ BMP family members, are suggested to regulate nearly every aspect of retinal development, such as proliferation, migration, fate determination, cell death and functional maturation $[26,27,29,58,59]$. Follistatin, a potent inhibitor of activin and several other members of the TGF $\beta$ super family have previously been implicated to take part in the differentiation of retinal neurons $[24,25,28]$. For instance, a recent study indicated that follistatin could interfere with the generation of neurons in the developing retina, and also showed that follistatin was able to down-regulate the activin-dependent pSmad2 [28].

The central-to-peripheral temporal gradient of retinal development, where the central regions of the retina are more mature relative the peripherally located regions, is well characterized and makes the spatio-temporal aspect of retinal development an important factor to consider. Therefore, to understand how follistatin activity in the retina relates to our birth-dating of HCs as well as to the appearance of the early HC marker Lim 1, we characterized the spatio-temporal follistatin expression. We found that follistatin expression followed a central-to-peripheral pattern and that with increasing age the immunoreactivity in the central retina decreased and an apparent wave-front of high follistatin expression moved towards to the periphery. The appearance of Lim $1+$ cells followed close behind this moving wave-front (Fig. 6C and 6D, black arrows). Combined with our qRT-PCR data demonstrating a dramatic 50-fold drop in follistatin mRNA levels that coincided with the time of $\mathrm{HC}$ birth, our observations show a correlation between low follistatin levels and HC generation.

In several cells and tissues, follistatin promotes proliferation by removing the inhibition of cell proliferation exerted by activin [42]. Our observations indicate that this is also true in the developing retina. For instance, activin injections in E3 embryos caused a robust decrease in BrdU incorporation (Fig. 7A-C), and during E2 (st14-18), which is a time marked by massive RPC proliferation in the developing retina, the relative levels of follistatin mRNA were extremely high (Fig. 6A). Combined, these observations indicate that follistatin stimulate proliferation in the retina, possibly by repressing activin signalling. Interestingly, the notion that follistatin stimulates proliferation may appear inconsistent with the observation that embryos injected with follistatin and analysed $22 \mathrm{~h}$ after the injection had fewer Lim1+ cells than control-treated embryos. Our interpretation is that the transient follistatin overexposure prevents HC-generating progenitor cells from producing post-mitotic cells, which turn on Lim1 expression. Instead, the affected progenitor cells may produce two mitotic daughters (not yet expressing Lim1) that will both inherit the capability to produce HCs. Thus, with a follistatin-induced increase of the HC-generating progenitor pool, the observed result will be a delayed onset of Lim 1 expression, followed by an increase in the total number of HCs at a later time point (e.g. at E9), and this is what our results showed. Combined, these observations suggest that follistatin is important for early RPC proliferation in general and specifically for the proliferation and generation of HC progenitor/precursor cells (Fig. 10B). However, since the follistatin-phenotype at E9 (st35) most often was restricted to distinct regions of the retina, this indicates the existence of a spatio-temporal window during which HC-generating progenitor cells are susceptible to follistatin treatment which give rise to the described effects.

Moreover, embryos injected with follistatin at E3 and analysed at E9 (st35) had a significantly increased number of HCs. This increase was slightly more pronounced in the later-born Isl $1+$ HCs (approximately $+50 \%$ ) compared to the early Lim $1+$ HCs (approximately $+40 \%$ ) (Fig. 8, compare $\mathrm{H}$ and I, see also Additional file 3). Furthermore, the ectopic HCs scattered within the retina at st35 in follistatin-treated retinas were predominantly of the Isl1 subtype (Fig. $8 \mathrm{~B}$ and $8 \mathrm{E}$ ). One day later, at st36, these ectopic cells were no longer observed and we concluded that they had settled in the HCL (Fig. 8B and $8 \mathrm{C}$ ), since the increased number of Prox1, Isl1 double positive HCs was similar in st35 and st36 retinas. Moreover, TUNEL staining was not detected in these cells (Fig. 8F). Our conclusion is that the ectopic and migrating HCs at st 35 represent HCs that were produced in excess following follistatin treatment. This is in agreement with a model wherein follistatin cause HCgenerating progenitor cells to proliferate beyond the normal period of HC generation, thus producing extra HCs that also migrate to the HCL.

Follistatin inhibits the action of ligands such as activin and other TGF $\beta$-signalling molecules by binding them and thus preventing subsequent receptor activation. Hence, the inhibitory effects of follistatin depend on the presence of these ligands. Activin and its receptors are known to be present in the developing retina [24] and therefore activin stands out as a likely candidate through which follistatin exerts its inhibitory action. However, it cannot be excluded that the effects caused by follistatin treatment are generated by the inhibition of other TGF $\beta$ signalling systems, or that the follistatin treatment may mediate its effects by indirectly influencing other cell signalling systems. Regardless of the pathway(s) by which follistatin affects retinal development at E3, our data suggest that the effects are exclusive to progenitor cells that generate HCs since we were unable to detect any differ- 
ences in the number of other retinal cell populations at E9 following follistatin treatment at st23 (Fig. 9G-I, see also Additional file 3). This was perhaps surprising, considering the broad spectrum of ligands which follistatin can bind and inhibit, and also considering that classic lineagetracing experiments have shown that early RPCs are homogeneously multipotent and capable of generating all retinal cell types $[60,61]$.

The result that the other major retinal cell populations studied were not affected by follistatin might, however, be explained by one or more mechanisms. First, compared to HCs, most retinal cell populations are generated over a long period of time, which allows for secondary mechanisms to control proliferation and cell-fate decisions. This can be exemplified by post-mitotic amacrine cells and ganglion cells that through feedback inhibition to progenitor cells control the continued generation of these cell types, respectively $[62,63]$. In addition, apoptosis may also provide a mechanism by which, from E3 to E9, cell numbers are adjusted and corrected. Secondly, the brief overexposure-time of follistatin in our experimental setup may be insufficient to produce effects that would require long-term follistatin exposure, and may explain the inconsistency between our and Moreira and Adler's observations that following their continuous follistatinoverexposure, the region containing Ap2 $\alpha$ amacrine cells decreased in thickness [28]. Thirdly, one may hypothesise that progenitor cells, which generate other retinal populations than HCs at E3 (for instance retinal ganglion cells and cone photoreceptors), rely on other signalling systems than follistatin to control their proliferation rate. Supporting this view are previous studies reporting that certain RPCs are biased to produce only a limited repertoire of neurons [56,64-66]. These three explanations are not mutually exclusive; however, based on our and other's data, we favour an explanation that assumes a degree of heterogeneity in the early RPC pool.

Horizontal cells are in several ways the odd ones out when compared to other retinal neurons. For example, HCs undergo bi-directional migration, and in contrast to most retinal cell populations, $\mathrm{HC}$ cell numbers are not adjusted by apoptosis, neither during early nor late development. As shown here, HCs are the only cell type that is affected by follistatin at E3, which suggests that progenitor cells that are competent to generate HCs are follistatin-sensitive, whereas progenitor cells that generate other earlyborn neurons, e.g. cone photoreceptors are not. In line with this, the existence of progenitor cells biased for HC generation have been indicated in mice [66] where Zhang et al. found using Cre-LoxP fate-mapping that an enhancer element of Pax 6 was active in a restricted subset of RPCs, which almost exclusively generated HCs. The recent work by Godinho et al in zebrafish [56] and the lin- eage study in chick by Rompani and Cepko [57] both shows that there are progenitor cells fated to generate HCs by a final mitosis. Rompani and Cepko's data suggest that such dedicated HC progenitors are biased to generate two HCs of only one subtype.

Our results showed that the generation of both Lim $1+$ and Isl $1+$ subtypes were affected by the follistatin injections at st20-23 (Fig. 8G-I). Assuming that the effect by the early bolus injection of follistatin is transient and that it is washed out before the peak of Isl1+ HC generation, our data agree with an interpretation that progenitors are committed to a HC fate before their terminal mitosis or even before they undergo their last S-phase. This interpretation is consistent with the observation that pre-mitotic $\mathrm{HC}$ precursors in zebrafish bear morphological resemblance to HCs themselves and also express Ptf1a and Cx55.5 that are normally found in post-mitotic HCs [56].

\section{Conclusion}

Axon-bearing and axon-less HC subtypes express Lim1 and Isl1, respectively. These two subtypes are born sequentially and their relative proportions are fixed early in development and are not adjusted by apoptosis. HCs are generated concomitantly with a decrease in endogenous follistatin levels. Adding exogenous follistatin at E3 clearly affected progenitor cells competent to generate HCs, and caused an over-production of HCs (Fig. 10B). Taken together, our data suggest that HC progenitors are sensitive to follistatin and become committed to produce Lim1+ and/or Isl1+ HC subtypes concomitantly with or early after their own generation.

\section{Methods \\ Animals and in ovo cultures}

Fertilized White Leghorn eggs (Gallus gallus) were obtained from Ova Produktion $\mathrm{AB}$ (Västerås, Sweden) and incubated at $38^{\circ} \mathrm{C}$ in a humidified incubator (Maino, Italy). Embryos were staged according to Hamburger and Hamilton [32]. Hatched chicks were kept at the animal facility at Evolutionsbiologiskt centrum, Uppsala. The animal work followed the EC guidelines and the ARVO statements for use of animals in ophthalmic and vision research. Experiments were scrutinized by the local animal ethics committee.

\section{Tissue preparation for immunohistochemistry}

Whole eyes or a patch of the central-most retina were dissected and fixed in 4\% PFA for 15-20 minutes, washed 10 minutes in PBS and cryoprotected in 30\% sucrose for 3-4 hours before being frozen in OCT (Sakura). Dissected retina was flat-mounted onto nitrocellulose filters. Tissues were cryosectioned and collected on Superfrost Plus glasses (Menzel-Gläser). Flat-mounts were cut in $10 \mu \mathrm{m}$ thick sections in a plane parallel to the filter producing 
sections through each retinal lamina. Cross-sections of the central retina were cut along the naso-temporal axis at 10 $\mu \mathrm{m}$ or $20 \mu \mathrm{m}$. Immunohistochemistry was preformed as described elsewhere [34].

\section{Antibodies}

Primary antibodies; Prox1 (1:1000, rabbit, AB5475, Chemicon), Lim1/2 (1:20, mouse, 4F2, Developmental studies hybridoma bank (DSHB)), Ap2 $\alpha$ (1:200, mouse, 3B5, DSHB), Pax6 (1:200, mouse, PAX6, DSHB and 1:4000, rabbit, AB5409, Chemicon), Isl1/2 (1:200, mouse, 40.2D6, DSHB, [67]) and Isl1 (1:10000, guinea pig, gift from Prof. J. Ericson), GABA (1:1000 rabbit, A2052, Sigma), Calretinin (1:1000, rabbit, 1741-1007, Anawa), TrkA (1:4000, rabbit, gift from Prof. L. Reichardt [68]), BrdU (1:500, mouse, B8434, Sigma), follistatin (1:100, goat, sc-23553, Santa Cruz) and Lim3 (1:200, mouse, 67.4E12, DSHB). Secondary antibodies were obtained from Vector Laboratories, Jackson Immunoresearch Laboratories or Molecular Probes.

\section{Microscopy and image processing}

Samples were analysed using a Zeiss Axioplan2 microscope or a Zeiss LSM 510 confocal microscope, equipped with Axiovision software or LSM 510 imaging software (v3.2), respectively. Images were formatted, resized, enhanced and arranged for publication using Axiovision, LSM image browser and Adobe Photoshop. Graphs were made in Prism (v3.02, GraphPad software Inc.).

\section{In ovo embryo cultures}

For the birth-dating experiment and follistatin/control injections, fertilized eggs were removed from the incubator on E2 or E3 and $3 \mathrm{ml}$ egg white was aspirated from the egg to allow the yolk and embryo to detach from the inside of the eggshell. A small window was made in the eggshell above the embryo and re-sealed with transpore tape ( $3 \mathrm{M})$. Embryos were returned to the incubator and allowed to develop until the desired stage when manipulations were carried out. After manipulation, the windows were again re-sealed with tape and the eggs returned to the incubator where the embryos were allowed to develop until the time of analysis.

\section{Intra ocular follistatin injections}

The eye of st20-23 (E3) embryos were microinjected with $<0,2 \mu \mathrm{l}$ follistatin (PeproTech, $1 \mu \mathrm{g} / \mu \mathrm{l}$ in PBS) using glass capillaries. Control injections contained vehicle. The solutions were supplemented with Fast Green (Kodak) in order to visualize the injected solution. Embryos were allowed to develop to st35-36 (E9-10) when injected eyes were processed for immunohistochemistry. The survival at st 35 was typically $20-30 \%$ for both vehicle and follistatin injections.
Upon macroscopic inspection, injected eyes appeared normal when compared to un-injected and contralateral eyes. Deviations from normal appearance were rare. Histologically, the follistatin phenotype was not evenly spread over the retina but rather confined to distinct zones, so in order to select regions for cell counting (see below) the histological phenotype described in the Results part served as our criteria to determine if a retinal region had been affected by the follistatin. Un-affected regions were most often found in the periphery. Approximately $20 \%$ of the follistatin treated survivors did not produce a clear histological phenotype and were omitted from further analysis.

\section{Cell quantification and statistical analysis}

The distribution of HC subtypes may vary with retinal location $[43,69]$, thus all cell counts were performed in samples taken from the central retina. The region directly opposite to the lens and/or in proximity to the optic nerve exit was considered as central retina. HC counts were based on the assumption that Prox1 labels all HCs.

Cell quantification in developing embryos: $10 \mu \mathrm{m}$ crosssections of normal, follistatin or vehicle injected eyes were labelled using immunohistochemistry as described above. For HC quantification in st35 and st36 embryos, fluorescence micrographs of sections with Prox1 labelling in combination with Lim1 or Isl1 were acquired using the $40 \times$ objective on an Axioplan 2 microscope. The number of cells positive for Prox1 alone, or Prox1, Lim1 double positive-, and Prox1, Isl1 double positive cells was determined from two series of injections using a minimum of 4 individuals surviving the injections per stage as indicated in figures and legends. A minimum of 4 micrographs from 4 retinal sections per animal were used for cell quantification, which was facilitated by Photoshop and Image $(\mathrm{NIH})$. Statistical analyses were performed in Prism (v3.02, GraphPad software Inc.) using the MannWhitney test and p-values $<0.05$ were considered significant (see also Additional file 3). For quantification of other cell populations than HCs following follistatin treatment, the same retinas used for HC quantification above were immuno-labelled using various markers. Cell counting and statistical analysis was done as described above.

To test the effects of follistatin injections on the number of Lim $1+$ cells early in development, st21, st22 and st23 eyes were injected with follistatin or vehicle as described above and processed for Lim 1 immunohistochemistry 22 $\mathrm{h}$ after the injections (number of animals analysed per stage is indicated in Fig. 6E and Additional file 3). Images from central retina were obtained from 5 sections per embryo using a $20 \times$ objective and the number of Lim $1+$ cells was quantified using Photoshop and ImageJ. The 
area of the cross-sections was determined using Axiovision and the density of Lim $1+$ cells in each section was expressed in cells $/ \mathrm{mm}^{2}$ retina. Statistical analyses were performed in Prism (v3.02, GraphPad software Inc.) using the Mann-Whitney test and p-values $<0.05$ where considered significant (see also Additional file 3 ).

HC subtype quantification at P0: Z-stacks $(\sim 0,4 \mu \mathrm{m}$ intervals) of the HCL were obtained from $20 \mu$ m thick retinal cross sections stained for Lim1, Isl1, Ap2 $\alpha$ combined with Prox1, GABA, calretinin or TrkA using a $63 \times$ objective in a LSM confocal microscope. Each Z-stack contained on average 75 HCs. From 3 P0 chick retinas, at least 4 regions in direct proximity to the optic nerve exit were photographed for each staining combination and the fractions of single- or double positive cells within the stack were counted manually using the LSM 510 imaging software.

\section{Birth-dating of horizontal cell subtypes}

Carefully staged embryos ranging from st19 to st33 received a single dose of tritiated deoxy-thymidine $\left(\left[{ }^{3} \mathrm{H}\right]-\right.$ $\mathrm{dT}, 1 \mu \mathrm{Ci} / \mu \mathrm{l}$, TRK758, Amersham). Stage 19-26 embryos received $15 \mu \mathrm{Ci}$, and st27-33 embryos received $25 \mu \mathrm{Ci}$. A minimum of three embryos per stage was used (except stages 32 and 33, see Fig. 2). Embryos were allowed to develop until st35, when the central most piece of retina was punched out using a sharpened metal tube $4.5 \mathrm{~mm}$ in diameter. Each retina was fixed (10 min, 4\% PFA), washed (10 min, PBS) and dissociated to a single-cell suspension in $0,25 \%$ trypsin. Cells were pelleted and resuspended in $1 \mathrm{ml}$ PBS (approximately $10^{6} \mathrm{cells} / \mathrm{ml}$ ). The cell suspensions were plated onto 8-well slides (PH-098, NovaKemi $\mathrm{AB}$, Sweden, $50 \mu \mathrm{l} /$ well) and air-dried. Slides were processed for Prox1 or Lim1 immunocytochemistry, using the Vectastain Elite ABC-kit (PK-6102) and the 3,3'-diaminobensidine (DAB) peroxidase substrate kit (SK-4100) from Vector Laboratories, according to the manufacturers instructions. Slides were pre-treated in $0,5 \%$ Cobalt(II)Chloride before the DAB reaction to maintain $\mathrm{DAB}$ staining through the autoradiographic processing [70]. Slides were dipped in EM Hypercoat Emulsion (RPN41, GE Healthcare) and left to expose in darkness for 6-8 days at $4{ }^{\circ} \mathrm{C}$ before being developed using Kodak D19 and Kodak Fixer (P6557, Sigma). Slides were mounted in Entellan (Merck) and analysed by light microscopy. The optimal exposure time was determined for each stage and the threshold that was considered as a positive $\left[{ }^{3} \mathrm{H}\right]-$ dT labelled cell was determined for each individual experiment by identifying the most heavily $\left[{ }^{3} \mathrm{H}\right]$-dT labelled cells per sample and using those cells as reference (see Additional file 1). On average, 260 immunolabelled cells per stage and antibody were counted.

In addition to the round HCs with strong nuclear Prox1 labelling, weak Prox1 labelling is found within the INL at st35 in elongated cells that are not HCs [33]. Therefore, a distinction between Prox1+ HCs and non-HCs was made; elongated faintly DAB-labelled cells were considered nonHCs whereas rounded intensely nuclear DAB-labelled cells were considered to be HCs (Additional file 1, compare cells in A-B with cells in C). Only cells with intense nuclear Prox1 labelling were counted.

Since Lim 1+ HCs constitute half of all Prox $1+$ HCs at st35 (Fig. 1B), the raw data obtained from Lim1 cell counts were divided by two. For example, if from one stage 15 out of $25 \mathrm{Lim} 1+$ cells were also $\left[{ }^{3} \mathrm{H}\right]-\mathrm{dT}+$, then this indicated that $60 \%$ of the Lim 1 expressing HCs were born around this time. However, since Lim $1+$ HCs at the time of analysis (st35) constitute half of all HCs, this number actually corresponds to $30 \%$ of all HCs with respect to Prox 1 . Thus, to relate the fraction of $\left[{ }^{3} \mathrm{H}\right]-\mathrm{dT}+\operatorname{Lim} 1$ cells to the fraction of $\left[{ }^{3} \mathrm{H}\right]-\mathrm{dT}+$ Prox 1 cells at the same stage, $30 \%$ (and not 60\%) would be the Lim1 percentage plotted in figure 2 for that specific stage (see also Additional file 3 ). Moreover, since we were unable to determine the birthcurve of Isl1+ HCs directly, the numerical difference between $\left[{ }^{3} \mathrm{H}\right]-\mathrm{dT}+$ Prox 1 and Lim 1 fractions were plotted as a line to represent the birth-curve of Isl1+ HCs. Statistical analysis using the Student's t-tests were preformed at every stage to test whether the $\left[{ }^{3} \mathrm{H}\right]-\mathrm{dT}+\operatorname{Prox} 1$ and Lim 1 fractions were significantly different $\left({ }^{*} \mathrm{p}<0.05\right)$.

\section{TUNEL in combination with immunohistochemistry}

To analyse cell death during retinal development we modified the protocol supplied with the DeadEnd Fluorometric TdT-mediated-dUTP-nick-end-labelling (TUNEL) system (G3250, Promega) to be combined with immunohistochemistry. Sections were labelled for Prox 1 and fixed in $4 \%$ PFA prior to TUNEL staining, and secondary antibodies were added after the TUNEL reaction. Retinas from all stages between st 20 and st 36 but also stages 39, 41, 42, 44, P0, P4 and P7 were analysed. In addition, follistatin and vehicle-treated retinas were analysed with respect to Prox1 and TUNEL at st35-36 (E9-10).

\section{Quantitative real time PCR}

Total RNA was extracted from embryonic tissues using the Trizol reagent (Invitrogen). Retinal tissue form stages 14, $16,18,21,23,25,28,30,35,38,42$ and 45 were used. For st14-18, optic cups from 20-40 embryos were collected and pooled with some contamination from lens and retinal pigment epithelium. For embryos older than st18, 214 retinas were collected and pooled. Two batches of cDNA were prepared separately from $1 \mu \mathrm{g}$ of RNA using GeneAmp ${ }^{\circledast}$ (Applied Biosystems). Samples were run in triplicate on both cDNA batches using $\mathrm{IQ}^{\mathrm{TM}} \mathrm{SyBr}^{\circledast}$ Green Supermix (Biorad) and normalized to $\beta$-actin and TATAbox binding protein. Control reactions containing primers but no RNA were analysed in parallel. Primer 
sequences were; $\beta$-actin (NM205518; 5'-aggtcatcaccattggcaatg-3' and 5'-cccaagaaagatggctggaa-3'), TATA-box binding protein (D83127; 5'-tagcccgatgatgccgtat-3' and 5'gttccetgtgtcgcttgc-3'), follistatin (NM205200, 5'-cgtcaacgacaacacgctctt-3' and 5'-ccaggtccacagtccacattct-3'), follistatin-like 1 (NM204638, 5'-attgtgagctgcaccgagatg-3' and 5'aactggactcgcagctggatt-3').

\section{BrdU-assay in early activin-treated retinas}

To test the effect of activin on retinal precursor cell proliferation we injected st 23 embryos with activin (PeproTech, $25-50 \mu \mathrm{g} / \mathrm{ml}$ in $5 \mathrm{mM}$ citric acid) or vehicle as described above. Five hours after injection, $100 \mu \mathrm{l}$ of $10 \mathrm{mg} / \mathrm{ml}$ BrdU (Sigma) was injected to the egg and 22 hours after the initial injection, embryos were analysed for BrdU incorporation by immunohistochemistry, with the modification that eyes were fixed in PFA for 1 hour. The number of BrdU+cells following activin $(n=5)$ or vehicle treatment $(n=4)$ were quantified from a minimum of 4 cross-sections per embryo using Photoshop and ImageJ. The area of the cross-sections of retina that were sampled for labelled cells was determined using Axiovision and the density of BrdU+ cells in each cross-section was expressed in cells $/ \mathrm{mm}^{2}$ retina. Statistical analyses was performed in Prism (v3.02, GraphPad software Inc.) using the MannWhitney test, $\mathrm{p}$-value $<0.05$ was considered significant.

\section{Authors' contributions}

PHE designed the experimental work, carried out immunostainings, $\left[{ }^{3} \mathrm{H}\right]$-dT birth-dating analysis, apoptosis analysis, BrdU-assay, did most intraocular injections and most cell counting, analysed the data, wrote the manuscript and made the figures. HB performed the qRT-PCR analysis and contributed to the manuscript. ML carried out intraocular injections and contributed to the manuscript. SML carried out $\left[{ }^{3} \mathrm{H}\right]$-dT birth-dating analysis and contributed to the manuscript. FH conceived of the study, designed and coordinated the work and wrote the manuscript. All authors read and approved its final version.

\section{Additional material}

\section{Additional file 1}

Representative cells from birth-dating experiment using [ $\left.{ }^{3} \mathrm{H}\right]-d \mathrm{~T}$ in combination with Prox1. High power bright-field micrograph of dissociated st35 retinal cells labelled for Prox1 (DAB colorimetric staining, brown) and processed for autoradiographical detection of $\left[{ }^{3} \mathrm{H}\right]-d \mathrm{~T}$ incorporation. Click here for file

[http://www.biomedcentral.com/content/supplementary/1471213X-8-46-S1.tiff]

\section{Additional file 2}

Follistatin expression in st34 retina. Follistatin immunoreactivity (red) in a st34 retina is restricted to the ganglion cell layer ( $\mathrm{gcl}$ ) and to certain cells located on the inner-most rim of the inner nuclear layer (inl). This pattern together with the observation that follistatin treatment cause a thinning of the inner plexiform layer (this study and ref [28]), and our data demonstrating that follistatin mRNA levels increase from st35 and beyond suggest that follistatin also has a function in the development, organization and/or establishment of the inner plexiform layer. Scale bar: $20 \mu \mathrm{m}$. Click here for file

[http://www.biomedcentral.com/content/supplementary/1471213X-8-46-S2.tiff]

\section{Additional file 3}

Data presented in figures 2 and 6 to 9. Data used for making graphs in figures 2, 6, 7, 8 and 9 .

Click here for file

[http://www.biomedcentral.com/content/supplementary/1471213X-8-46-S3.pdf]

\section{Acknowledgements}

We thank Ulf Hedström for his help in developing TUNEL-immunohistochemistry protocols; Johan Ericson and Louis Reichardt for IsII and TrkA antibodies. Funding for this work was obtained from the Swedish Research Council (12187, I4386), Kronprinsessan Margaretas arbetsnämnd för synskadade, Research Foundation Wallenberg Consortium North and The Swedish Strategic Research foundation.

\section{References}

I. Kahn AJ: An autoradiographic analysis of the time of appearance of neurons in the developing chick neural retina. Dev Biol 1974, 38(I):30-40.

2. Rapaport DH, Wong LL, Wood ED, Yasumura D, LaVail MM: Timing and topography of cell genesis in the rat retina. J Comp Neurol 2004, 474(2):304-324.

3. Young RW: Cell differentiation in the retina of the mouse. Anat Rec 1985, 21 2(2): 199-205.

4. Kolb H, Nelson R, Ahnelt $\mathrm{P}$, Cuenca $\mathrm{N}$ : Cellular organization of the vertebrate retina. In Concepts and challenges in retinal biology: a tribute to John E Dowling (Progress in Brain Research 131) Volume I3I. Edited by: Kolb H, Ripps H, Wu S. Amsterdam, Elsevier; 200I:3-26.

5. Masland RH: Neuronal diversity in the retina. Curr Opin Neurobiol 200I, I I (4):43I-436.

6. Gallego A: Chapter 7 Comparative studies on horizontal cells and a note on microglial cells. Progress in Retinal Research 1986, 5:165-206.

7. Peichl L, Sandmann D, Boycott BB: Comparative anatomy and function of mammalian horizontal cells. In Development and Organization of the Retina From Molecules to Function Volume 299. Edited by: Chalupa LM, Finlay BL. New York, Plenum Press; 1998:147-I72.

8. Peichl L, Gonzalez-Soriano J: Morphological types of horizontal cell in rodent retinae: a comparison of rat, mouse, gerbil, and guinea pig. Vis Neurosci 1994, I I(3):50 I-5I7.

9. Connaughton VP, Graham D, Nelson R: Identification and morphological classification of horizontal, bipolar, and amacrine cells within the zebrafish retina. J Comp Neurol 2004, 477(4):37I-385.

10. Cuenca N, Haverkamp $\mathrm{S}$, Kolb $\mathrm{H}$ : Choline acetyltransferase is found in terminals of horizontal cells that label with GABA, nitric oxide synthase and calcium binding proteins in the turtle retina. Brain Res 2000, 878(I-2):228-239.

II. Kolb H, Fernandez E, Schouten J, Ahnelt P, Linberg KA, Fisher SK: Are there three types of horizontal cell in the human retina? J Comp Neurol 1994, 343(3):370-386. 
12. Mariani AP: Neuronal and synaptic organization of the outer plexiform layer of the pigeon retina. Am J Anat 1987, I 79(I):25-39.

13. Genis-Galvez JM, Prada F, Armengol JA: Evidence of three types of horizontal cells in the chick retina. Jpn J Ophtamol 1979, 23(4):378-387.

14. Tanabe K, Takahashi Y, Sato Y, Kawakami K, Takeichi M, Nakagawa $\mathrm{S}$ : Cadherin is required for dendritic morphogenesis and synaptic terminal organization of retinal horizontal cells. Development 2006.

I5. Zhang AJ, Zhang J, Wu SM: Electrical coupling, receptive fields, and relative rod/cone inputs of horizontal cells in the tiger salamander retina. J Comp Neurol 2006, 499(3):422-43 I.

16. Zhang J, Zhang AJ, Wu SM: Immunocytochemical analysis of GABA-positive and calretinin-positive horizontal cells in the tiger salamander retina. J Comp Neurol 2006, 499(3):432-44I.

17. Dullin JP, Locker M, Robach M, Henningfeld KA, Parain K, Afelik S Pieler T, Perron M: Ptfla triggers GABAergic neuronal cell fates in the retina. $B M C$ Dev Biol 2007, 7(I): I I0.

18. Dyer MA, Livesey FJ, Cepko CL, Oliver G: Prox I function controls progenitor cell proliferation and horizontal cell genesis in the mammalian retina. Nat Genet 2003, 34(I):53-58

19. Fujitani Y, Fujitani S, Luo H, Qiu F, Burlison J, Long O, Kawaguchi $Y$ Edlund $H$, Macdonald RJ, Furukawa T, Fujikado T, Magnuson MA Xiang $M$, Wright CV: Ptfla determines horizontal and amacrine cell fates during mouse retinal development. Development 2006, I33(22):4439-4450.

20. Li S, Mo Z, Yang X, Price SM, Shen MM, Xiang M: Foxn4 controls the genesis of amacrine and horizontal cells by retinal progenitors. Neuron 2004, 43(6):795-807.

21. Nakhai H, Sel S, Favor J, Mendoza-Torres L, Paulsen F, Duncker GI, Schmid RM: Ptfla is essential for the differentiation of GABAergic and glycinergic amacrine cells and horizontal cells in the mouse retina. Development 2007, |34(6): | |5|-| |60.

22. Cunningham JJ, Levine EM, Zindy F, Goloubeva O, Roussel MF, Smeyne RJ: The cyclin-dependent kinase inhibitors p I 9(Ink4d) and p27(Kip I) are coexpressed in select retinal cells and act cooperatively to control cell cycle exit. Mol Cell Neurosci 2002, I 9(3):359-374.

23. Mehler MF, Mabie PC, Zhang D, Kessler JA: Bone morphogenetic proteins in the nervous system. Trends Neurosci 1997 20(7):309-317.

24. Belecky-Adams TL, Scheurer D, Adler R: Activin family members in the developing chick retina: expression patterns, protein distribution, and in vitro effects. Dev Biol 1999, 2 I 0(I): 107-123.

25. Davis AA, Matzuk MM, Reh TA: Activin A promotes progenitor differentiation into photoreceptors in rodent retina. Mol Cell Neurosci 2000, I5(I): | |-2|

26. Franke AG, Gubbe C, Beier M, Duenker N: Transforming growth factor-beta and bone morphogenetic proteins: Cooperative players in chick and murine programmed retinal cell death. J Comp Neurol 2006, 495(3):263-278.

27. Kim J, Wu HH, Lander AD, Lyons KM, Matzuk MM, Calof AL: GDF I controls the timing of progenitor cell competence in developing retina. Science 2005, 308(5730): 1927-1930.

28. Moreira EF, Adler R: Effects of follistatin overexpression on cell differentiation in the chick embryo retina. Dev Biol 2006, 298(I):272-284

29. Murali D, Yoshikawa S, Corrigan RR, Plas DJ, Crair MC, Oliver G Lyons KM, Mishina Y, Furuta Y: Distinct developmental programs require different levels of $\mathrm{Bmp}$ signaling during mouse retinal development. Development 2005, I 32(5):913-923.

30. Sakuta H, Suzuki R, Takahashi H, Kato A, Shintani T, lemura S, Yamamoto TS, Ueno N, Noda M: Ventroptin: a BMP-4 antagonist expressed in a double-gradient pattern in the retina. Science 200I, 293(5527): I II-II5.

31. Phillips DJ, de Kretser DM: Follistatin: a multifunctional regulatory protein. Front Neuroendocrinol 1998, I9(4):287-322.

32. Hamburger $V$, Hamilton HL: A series of normal stages in the development of the chick embryo. I Morphol I95I, 88:49-92.

33. Edqvist PH, Myers SM, Hallbook F: Early identification of retinal subtypes in the developing, pre-laminated chick retina using the transcription factors ProxI, Lim I, Ap2a, Pax6, IsII, IsI2, Lim3 and ChxI0. European Journal of Histochemistry 2006, 50(2): $\mid 47-154$.
34. Edqvist PH, Hallböök F: Newborn horizontal cells migrate bidirectionally across the neuroepithelium during retinal development. Development 2004, I 3 I (6): | 343-I35 I

35. da Costa Calaza K, Hokoc JN, Gardino PF: Neurogenesis of GABAergic cells in the chick retina. Int J Dev Neurosci 2000, | 8(8):72|-726.

36. Ellis $\mathrm{J}$, Richards $\mathrm{DE}$, Rogers $\mathrm{JH}$ : Calretinin and calbindin in the retina of the developing chick. Cell Tissue Res 1991, 264(2): 197-208.

37. Karlsson M, Clary DO, Lefcort FB, Reichardt LF, Karten HJ, Hallbook $F$ : Nerve growth factor receptor TrkA is expressed by horizontal and amacrine cells during chicken retinal development. J Comp Neurol 1998, 400(3):408-4I6.

38. Fischer AJ, Stanke JJ, Aloisio G, Hoy H, Stell WK: Heterogeneity of horizontal cells in the chicken retina. J Comp Neurol 2007 500(6): | | 54- I I7|

39. Karten H, Reichardt LF, Clary DO, Keyser KT: Trk A receptors reveal a new class of non-GABAergic horizontal cells in the avian retina [abstract]. Arvo abstracts, Invest Opthalmol Vis Sci 1995, 36:256.

40. Liu W, Wang JH, Xiang M: Specific expression of the LIM/homeodomain protein Lim-I in horizontal cells during retinogenesis. Dev Dyn 2000, 2 I 7(3):320-325.

4I. Yazulla S: Chapter I GABAergic mechanisms in the retina. Progress in Retinal Research 1986, 5: I-52.

42. Chen YG, Lui HM, Lin SL, Lee JM, Ying SY: Regulation of cell proliferation, apoptosis, and carcinogenesis by activin. Exp Biol Med (Maywood) 2002, 227(2):75-87.

43. Sun $H$, Crossland WJ: Quantitative assessment of localization and colocalization of glutamate, aspartate, glycine, and GABA immunoreactivity in the chick retina. Anat $\operatorname{Rec} 2000$, 260(2): I58-179.

44. Genis-Galvez JM, Garcia-Lomas V, Prada F, Armengol JA: Developmental study of axon formation in the horizontal neurons of the retina of the chick embryo. Anat Embryol (Berl) 198I, I 6 I (3):319-327.

45. Nag TC, Wadhwa S: Differential expression of syntaxin-I and synaptophysin in the developing and adult human retina. J Biosci 200I, 26(2): |79-191.

46. Scheibe R, Schnitzer J, Rohrenbeck J, Wohlrab F, Reichenbach A Development of A-type (axonless) horizontal cells in the rabbit retina. I Comp Neurol I995, 354(3):438-458.

47. Messersmith EK, Redburn DA: The role of GABA during development of the outer retina in the rabbit. Neurochem Res 1993 I 8(4):463-470.

48. Loeliger M, Rees S: Immunocytochemical development of the guinea pig retina. Exp Eye Res 2005, 80(I):9-2I.

49. Nag TC, Wadhwa S: Expression of GABA in the fetal, postnatal, and adult human retinas: an immunohistochemical study. Vis Neurosci 1997, I4(3):425-432.

50. Rowe-Rendleman C, Mitchell CK, Habrecht M, Redburn DA Expression and downregulation of the GABAergic phenotype in explants of cultured rabbit retina. Invest Ophthalmol Vis Sci 1996, 37(6): 1074-1083.

51. Versaux-Botteri C, Pochet R, Nguyen-Legros J: Immunohistochemical localization of GABA-containing neurons during postnatal development of the rat retina. Invest Ophthalmol Vis Sci 1989, 30(4):652-659.

52. Vecino E, Hernandez M, Garcia M: Cell death in the developing vertebrate retina. Int I Dev Biol 2004, 48(8-9):965-974

53. Cook B, Portera-Cailliau C, Adler R: Developmental neuronal death is not a universal phenomenon among cell types in the chick embryo retina. J Comp Neurol 1998, 396(I): I2- I9.

54. Karlsson M, Mayordomo R, Reichardt LF, Catsicas S, Karten H, Hallbook F: Nerve growth factor is expressed by postmitotic avian retinal horizontal cells and supports their survival during development in an autocrine mode of action. Development 200I, I 28(4):47I-479.

55. Mayordomo R: Differentiated horizontal cells seem not to be affected by apoptosis during development of the chick retina. Int J Dev Biol 200I, 45(SI):S79-S80.

56. Godinho L, Williams PR, Claassen Y, Provost E, Leach SD, Kamermans $M$, Wong RO: Nonapical symmetric divisions underlie horizontal cell layer formation in the developing retina in vivo. Neuron 2007, 56(4):597-603. 
57. Rompani SB, Cepko CL: Retinal progenitor cells can produce restricted subsets of horizontal cells. Proc Natl Acad Sci U S A 2008, I05(I): 192-197.

58. Livesey F], Cepko CL: Vertebrate neural cell-fate determination: lessons from the retina. Nat Rev Neurosci 200I, 2(2): 109-118.

59. Yang XJ: Roles of cell-extrinsic growth factors in vertebrate eye pattern formation and retinogenesis. Semin Cell Dev Biol 2004, I5(I):9I-I03.

60. Turner DL, Snyder EY, Cepko CL: Lineage-independent determination of cell type in the embryonic mouse retina. Neuron 1990, 4(6):833-845.

61. Wetts R, Fraser SE: Multipotent precursors can give rise to all major cell types of the frog retina. Science 1988, 239(4844): I|42-I|45.

62. Belliveau MJ, Cepko CL: Extrinsic and intrinsic factors control the genesis of amacrine and cone cells in the rat retina. Development 1999, I 26(3):555-566.

63. Gonzalez-Hoyuela M, Barbas JA, Rodriguez-Tebar A: The autoregulation of retinal ganglion cell number. Development 200I, 128(I): I17-124.

64. Alexiades MR, Cepko CL: Subsets of retinal progenitors display temporally regulated and distinct biases in the fates of their progeny. Development 1997, I24(6): I | 19-II3I.

65. Moody SA, Chow I, Huang S: Intrinsic bias and lineage restriction in the phenotype determination of dopamine and neuropeptide $Y$ amacrine cells. J Neurosci 2000, 20(9):3244-3253.

66. Zhang X, Heaney S, Maas RL: Cre-loxp fate-mapping of Pax6 enhancer active retinal and pancreatic progenitors. Genesis 2003, 35(I):22-30.

67. Tsuchida T, Ensini M, Morton SB, Baldassare M, Edlund T, Jessell TM, Pfaff SL: Topographic organization of embryonic motor neurons defined by expression of LIM homeobox genes. Cell 1994, 79(6):957-970.

68. Lefcort F, Clary DO, Rusoff AC, Reichardt LF: Inhibition of the NT-3 receptor TrkC, early in chick embryogenesis, results in severe reductions in multiple neuronal subpopulations in the dorsal root ganglia. J Neurosci 1996, I6(I I):3704-37I3.

69. Lohrke S, Brandstatter JH, Boycott BB, Peichl L: Expression of neurofilament proteins by horizontal cells in the rabbit retina varies with retinal location. J Neurocytol 1995, 24(4):283-300.

70. Hermanson O, Ericson H, Sanchez-Watts G, Watts AG, Blomqvist A Autoradiographic visualization of 35S-labeled cRNA probes combined with immunoperoxidase detection of choleragenoid: a double-labeling light microscopic method for in situ hybridization and retrograde tract tracing. J Histochem Cytochem 1994, 42(6):827-831.
Publish with Biomed Central and every scientist can read your work free of charge

"BioMed Central will be the most significant development for disseminating the results of biomedical research in our lifetime. "

Sir Paul Nurse, Cancer Research UK

Your research papers will be:

- available free of charge to the entire biomedical community

- peer reviewed and published immediately upon acceptance

- cited in PubMed and archived on PubMed Central

- yours - you keep the copyright
BioMedcentral 